Paper intended for publication in the special issue of Waste Management "Landfill Gas Emission Monitoring".

\title{
AERMOD as a Gaussian dispersion model for planning tracer gas dispersion tests for landfill methane emission quantification
}

Matacchiera $^{\mathrm{a}}$, F., Manes ${ }^{\mathrm{b}}$, C., Beaven ${ }^{\mathrm{c}}$, R.P., Rees-White ${ }^{\mathrm{c}}$, T.C., Boano ${ }^{\mathrm{b}}$, F., Mønster ${ }^{\mathrm{d}}$, J., and Scheutz ${ }^{\mathrm{d}}, \mathrm{C}$.

${ }^{\text {a }}$ School of Planning and Environmental Policy, University College Dublin, Belfield, Dublin 4, Ireland.

${ }^{\mathrm{b}}$ Department of Environment, Land and Infrastructure Engineering, Politecnico di Torino, Corso Duca degli Abruzzi, 24, 10129, Torino, Italy.

${ }^{\mathrm{c}}$ Faculty of Engineering and the Environment, University of Southampton, Southampton, SO17 1BJ, UK.

${ }^{\mathrm{d}}$ Department of Environmental Engineering, Technical University of Denmark, 2800 Kgs. Lyngby, Denmark.

\begin{abstract}
The measurement of methane emissions from landfills is important to the understanding of landfills' contribution to greenhouse gas emissions. The Tracer Dispersion Method (TDM) is becoming widely accepted as a technique, which allows landfill emissions to be quantified accurately provided that measurements are taken where the plumes of a released tracer-gas and landfill-gas are well-mixed. However, the distance at which full mixing of the gases occurs is generally unknown prior to any experimental campaign.

To overcome this problem the present paper demonstrates that, for any specific TDM application, a simple Gaussian dispersion model (AERMOD) can be run beforehand to help determine the distance from the source at which full mixing conditions occur, and the likely associated measurement errors. An AERMOD model was created to simulate a series of TDM trials carried out at a UK landfill, and was benchmarked against the experimental data obtained. The model was used to investigate the impact of different factors (e.g. tracer cylinder placements, wind directions, atmospheric stability parameters) on TDM results to identify appropriate experimental set ups for different conditions.

The contribution of incomplete vertical mixing of tracer and landfill gas on TDM measurement error was explored using the model. It was observed that full mixing conditions at ground level do not imply full
\end{abstract}


mixing over the entire plume height. However, when full mixing conditions were satisfied at ground level, then the error introduced by variations in mixing higher up were always less than $10 \%$.

Keywords: Modelling, Tracer dispersion method, Full mixing distance, vertical mixing, GHG emissions. 


\section{INTRODUCTION}

Methane is a significant contributor to climate change, with a global warming potential 28 times higher than carbon dioxide if considered over a 100-year period [IPCC, 2014]. The European Environment Agency (EEA) reports that the decomposition of solid waste in landfills contributes up to $31 \%$ of the total emissions of methane from anthropogenic sources [GMI, 2013]. Monitoring helps comply with the European pollutant release and transfer register [E-PRTR, 2006], which requires reporting of the amount of pollutants released to the atmosphere from industrial facilities incl. landfills.

Several experimental methods have been developed to quantify methane emissions from landfills. Among them, the static flux chamber [Chan et al., 1998; Czepiel et al., 1996; Hutchinson \& Mosier, 1981], the dynamic flux chamber [Abichou et al., 2006] and the differential adsorption LiDAR [Babilotte et al., 2010; Robinson et al., 2011] are well-established techniques. The tracer dispersion method (TDM) [Babilotte et al., 2010; Czepiel et al., 2003; 1996; Foster-Wittig et al., 2015; Mønster et al., 2014; 2015; Scheutz et al., 2011] uses tracer gas that is released from gas cylinders placed on the site emitting methane. Methane and tracer gas concentrations are measured in transects downwind from the emission source. Assuming full mixing conditions, the unknown methane emission rate $\left(Q_{C H 4}\right)$ can be computed as:

$$
Q_{C H 4}=Q_{t r} \cdot \frac{\int_{x_{1}}^{x_{2}} C_{C H 4}(x) d x}{\int_{x_{1}}^{x_{2}} C_{t r}(x) d x} \frac{M W_{C H 4}}{M W_{t r}}
$$

where $Q_{t r}$ is the tracer mass emission rate (e.g. $\left.\mathrm{kg} / \mathrm{h}\right), x_{1}$ and $x_{2}$ are the starting and ending location of the transect measurements, $C_{C H 4}(x)$ and $C_{t r}(x)$ are respectively the volumetric methane and tracer gas cross-plume concentrations (e.g. ppmv) above background and $M W_{C H 4}$ and $M W_{t r}$ are the molar weights of methane and tracer gas respectively.

The gas concentrations are usually measured by means of portable instrumentation that is mounted on a vehicle, which is driven through the plumes downwind of the landfill-source [Mønster et al., 2014].

The TDM is considered a reliable and cost-effective alternative to existing and well established monitoring methods [Babilotte et al., 2010]. However, its use is still hampered by a number of technical difficulties.

In particular, the TDM requires concentration measurements at transects where the methane and the tracer gas plumes overlap and are fully or well-mixed. The distance downwind of the landfill where these conditions begin to be satisfied is referred to as the Full Mixing Distance (FMD). Interpreting data collected in the absence of well-mixed conditions can lead to substantial errors in the measured flux (e.g. Taylor et al., 2016). Equally, the further away the FMD is from the source, the more dilute the tracer and methane source gas will be making it more difficult to detect above their background concentrations, and the higher is the probability that the methane plume will be influenced by other methane-sources. 
The FMD does not depend only on meteorological conditions (which dictates mixing in the atmosphere), but also by other factors including the heterogeneity in the methane source, the number and placement of tracer-gas cylinders on the landfill, and by topography [Mønster et al., 2014; Taylor et al., 2016].

Given this dependency on so many variables, in practical applications, the FMD is never known a-priori and is commonly identified by trial and error. This may involve performing measurements over many transects at different downwind distances from the landfill. This increases the time and cost of a TDM survey release trial. Furthermore, full-mixing conditions are confirmed by interpolating (i.e. correlating) concentration measurements of tracer gas and methane at ground level. It is a tacit assumption of TDM campaigns that if full mixing occurs at ground level then the full mixing condition will also occur at higher altitudes. Although a previous study [Delkash et al., 2016] investigated gas concentrations above ground level, the variation in mixing conditions along a vertical profile have not been investigated (either experimentally or by modelling) and this ultimately adds uncertainty to the reliability of a TDM survey.

This paper intends to mitigate such difficulties and shortcomings associated with the TDM. We propose that, for any specific application (e.g. a landfill site), simple Gaussian dispersion models can be run beforehand to help determine the distance from the source at which full mixing conditions occur, the likely associated measurement errors and how dependent the FMD will be to different experimental conditions (e.g. different tracer cylinder placements, wind directions, atmospheric stability parameters) so that it is possible to identify appropriate experimental setups for different conditions. Ideally, such calculations require knowledge of the emission patterns and rates, which is unlikely to be known before the TDM survey, meaning that major assumptions need to be made. End members of different scenarios could include evenly distributed emissions over the whole site, and a "worst case scenario" which might be based on point source emissions from the operational area. Gaussian models are quick to run. For the purpose of experimentplanning their use is preferred over more complex models, including transient models, as they allow a wide range of scenarios to be explored in very little time.

To test this hypothesis, TDM experiments were carried out on a UK landfill [Rees-White et al., 2018] to provide benchmark data to assess whether the open-source Gaussian dispersion model AERMOD [Cimorelli et al., 2004] could be successfully employed to predict FMDs and associated measurement errors. AERMOD was selected over other possible models as it is the preferred steady state dispersion model of the US EPA and is free to use.

A range of simulations were performed using AERMOD to investigate the dependence on a number of variables on FMD, including: the surface roughness, the atmospheric stability conditions and the number and positioning of tracer gas cylinders. The aim was to identify general and straightforward guidelines that can be used to help perform successful TDM experiments, whilst recognising that there may still be a need for Gaussian dispersion models for certain site specific planning and interpretation tasks. 


\section{METHODOLOGY}

\subsection{Model setup and simulations}

Simulations were carried out using the Gaussian AMS/EPA Regulatory Model, AERMOD, developed by the American Meteorological Society (AMS) and the U.S. Environment Protection Agency (EPA) [EPA, 2016]. AERMOD overcomes the simplifications of Gaussian assumptions by introducing algorithms that improve the reliability and functionality of the model compared with other more simplified models that have been used in previous studies [Mønster et al., 2014; Fredenslund et al., 2017]. AERMOD can analyse the dispersion of pollutants in rural and urban areas, in flat or complex terrains, using point, area and volume sources. The software requires meteorological and terrain inputs, which are obtained by a meteorological pre-processor, AERMET, and a terrain pre-processor, AERMAP. AERMOD requires surface air and upper air data (e.g. wind speed, direction, temperature, pressure and solar radiation), which can be obtained from meteorological stations and soundings. Where upper air data is not available, as in this case, AERMOD uses an algorithm to extrapolate from surface data. The data are processed to obtain output files compatible with AERMOD and can be used both in convective and stable atmospheric conditions. AERMAP requires a Digital Elevation Model (DEM) and the coordinates of the source and receptors. Data are elaborated to create representative heights of the receptors, considering the influence of the topography on the dispersion processes. AERMOD processes the input data and furnishes the pollutant concentration values at the location of the receptors.

In this study a DEM with a $5 \mathrm{~m}$ resolution (Digimap ${ }^{\circledR}$ Ordnance Survey Terrain 5 SHAPE file) was used and meteorological data were obtained from an on-site-weather station. The source areas emitting methane (described further in section 2.2), were modelled as polygons superimposed onto the DEM. Tracer gas release was modelled as point sources 0.7 metres above ground level, again according to the location of different combinations of tracer gas cylinders as shown in Fig. 1. The range of simulations undertaken included: a sensitivity analysis; the calibration of the AERMOD landfill model using the known release of tracer gas from point sources; and the application of the calibrated model to interpret TDM surveys at the site.

Further simulations, for the purpose of analysis and discussion, were run to investigate: the effect of vertical full mixing condition on TDM results; the influence of surface roughness on the downwind distance at which TDM surveys should be carried out; the influence of meteorological parameters on the downwind distance at which TDM surveys should be carried out; and the influence of tracer gas cylinder placement and wind direction on measurement error. 


\subsection{TDM experiments}

Tracer gas release experiments were carried out at a landfill in south-east of UK, hereafter referred to as the study site. The landfill area is approximately $330,000 \mathrm{~m}^{2}$ with three sub-areas, as shown in Fig. 1: a fully restored area with an MDPE top liner and restoration soils, a partially restored area with an MDPE liner, but no soils, and a small operational area in the centre of the site. A Gas Utilisation Plant (GUP) is located in the south-east of the landfill.

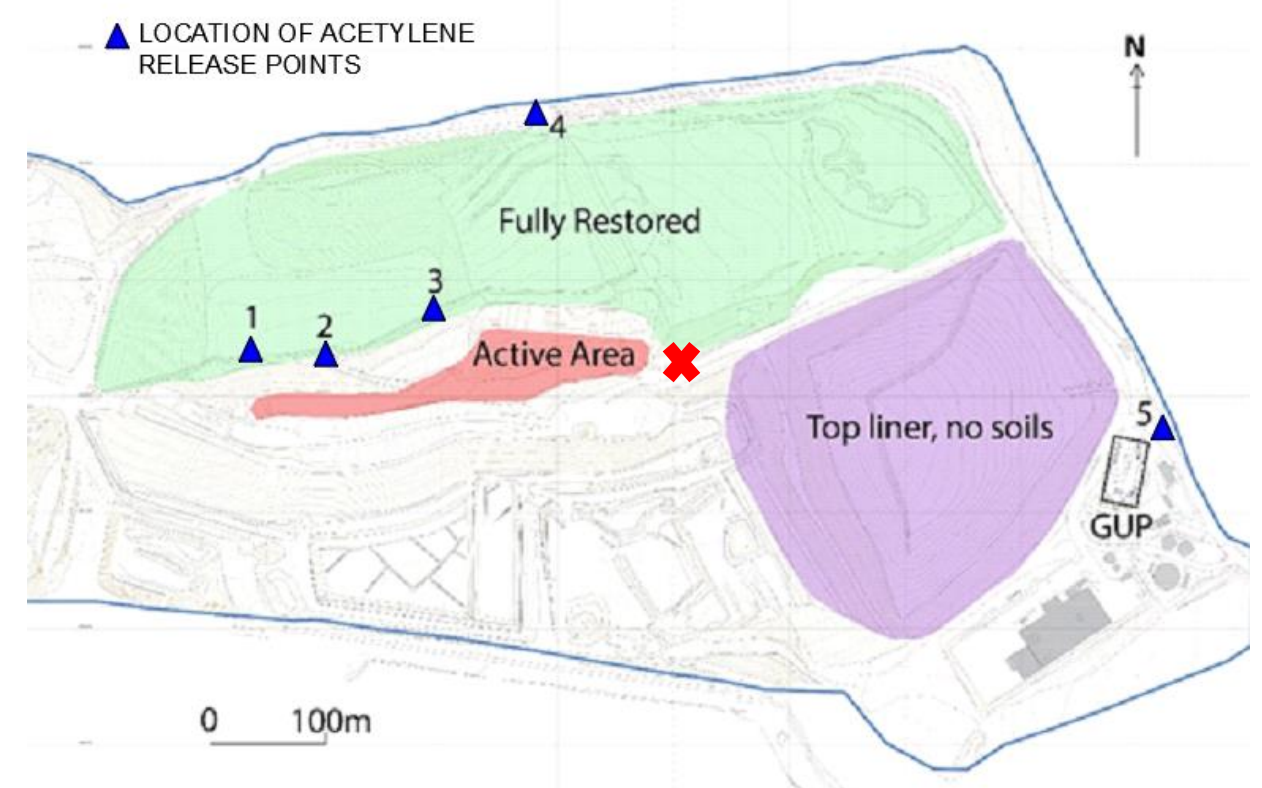

Fig. 1. Plan of the landfill showing fully and partly restored areas, the active (operational) filling area and the location of the tracer gas cylinders (triangles). Each area is modelled to have the same homogenous methane release rate. The red cross indicates the landfill centre "reference point" referred to in modelling.

A TDM campaign was carried out to quantify methane emissions from the landfill in August 2014 [Rees-White et al., 2018]. Measurements were performed over five days during changing meteorological conditions (e.g. wind speed, wind direction, solar radiation). Acetylene $\left(\mathrm{C}_{2} \mathrm{H}_{2}\right)$ was used as the tracer gas with between three and four cylinders used in combination from five different locations to emulate the landfill emission as shown in Fig. 1. The number of cylinders used, and the release location was dependent on the wind direction. On-site and remote gas concentrations were measured using cavity ring-down spectroscopy [Mønster et al., 2014, Rees-White et al., 2018] at different distances and directions from the landfill, depending on the wind direction and the availability of roads (Fig. 2). Between 15 and 20 plume transects were performed for a given tracer gas release [Rees-White et al., 2018].

Over the course of the TDM, wind speed and direction were measured adjacent to the GUP (Fig. 1) from a weather station mounted $\sim 5 \mathrm{~m}$ above the ground. Values reported are 30 minute averages of readings taken at $1 \mathrm{~Hz}$ frequency. 


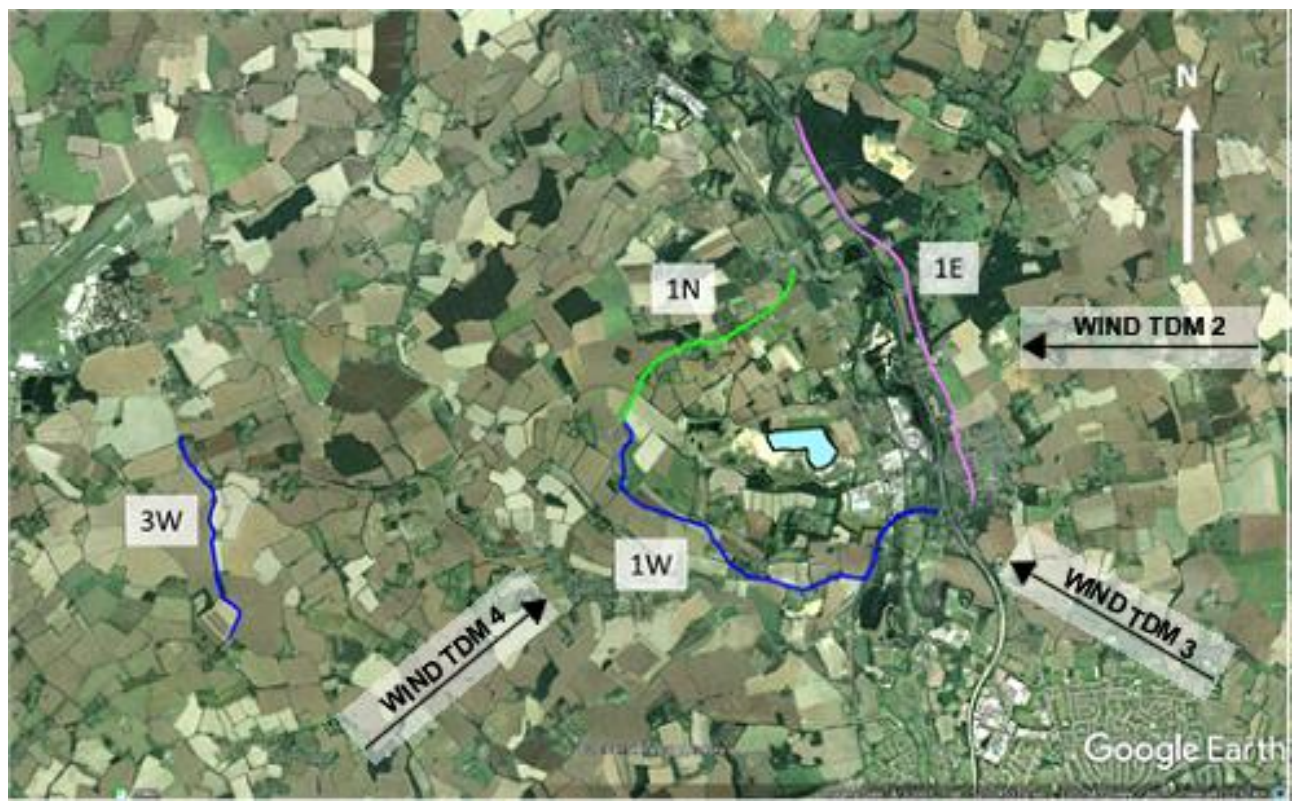

Fig. 2. A Google Earth image showing land use (terrain) around the landfill, monitoring routes used during the campaign to collect concentration data, and average wind direction during each release (Google, 2017). TDM 2, 3, and 4 refer to measurements performed 7th, 8th, and 11th August, respectively.

\section{RESULTS}

\subsection{Sensitivity analysis of the model}

AERMOD requires a number of estimated surface parameters, including: surface roughness (Z0), albedo (A) and Bowen ratio (BR). Although the User's Guide for the model provides a range of values for these parameters depending on season, land use (terrain) and moisture condition, it was considered important to assess their influence (Table 1) on the model output. In this way the error resulting from performing simulations with incorrect values of surface parameters could be evaluated.

Fig. 3 illustrates that AERMOD is particularly sensitive to the choice of the surface roughness (Fig. 3a), whereas it has very low sensitivity to the albedo (Fig. 3b) and Bowen ratio (Fig. 3c). The higher the value of the surface roughness, the wider the plume at any given location. This is because surfaces that are rougher favour mechanically-generated turbulence and hence scalar dispersion [Cimorelli et al., 2004; Michálek et al., 2012].

This analysis shows that AERMOD should be calibrated mainly in terms of the surface roughness (Z0), as the influence of other surface characteristics, such as albedo and Bowen ratio, are minimal. This is in line with previous literature on AERMOD [Grosch \& Lee, 1999; Karvounis et al., 2007; Long et al., 2003; Faulkner et al., 2008)] and allows a substantial simplification of the model calibration procedure. Subsequent modelling in this paper used representative values of albedo $(=0.20)$ and Bowen ratio $(=0.80)$, according to the values suggested by AERMET User's Guide. 
Table 1. Range of values for surface roughness (ZO), albedo (A) and Bowen ratio (BR) used in the sensitivity analysis.

\begin{tabular}{|c|c|c|}
\hline Variable parameter & Justification & Constant parameters \\
\hline $0.001 \mathrm{~m} \leq \mathrm{Z} 0 \leq 0.2 \mathrm{~m}$ & $\begin{array}{c}\text { Surrounding land use varies from grassland in winter } \\
(\mathrm{Z} 0=0.001) \text { to cultivated land in summer }(\mathrm{Z} 0=0.2)\end{array}$ & $\mathrm{BR}=0.8, \mathrm{~A}=0.2$ \\
\hline $0.2 \leq \mathrm{BR} \leq 3$ & $\begin{array}{c}\text { The Bowen ratio range chosen covers all land use } \\
\text { types other than desert and urban land use }\end{array}$ & $\mathrm{Z} 0=0.01, \mathrm{~A}=0.2$ \\
\hline $0.14 \leq \mathrm{A} \leq 0.50$ & The values of albedo chosen cover all land use types & $\mathrm{Z} 0=0.01, \mathrm{BR}=0.8$ \\
\hline
\end{tabular}

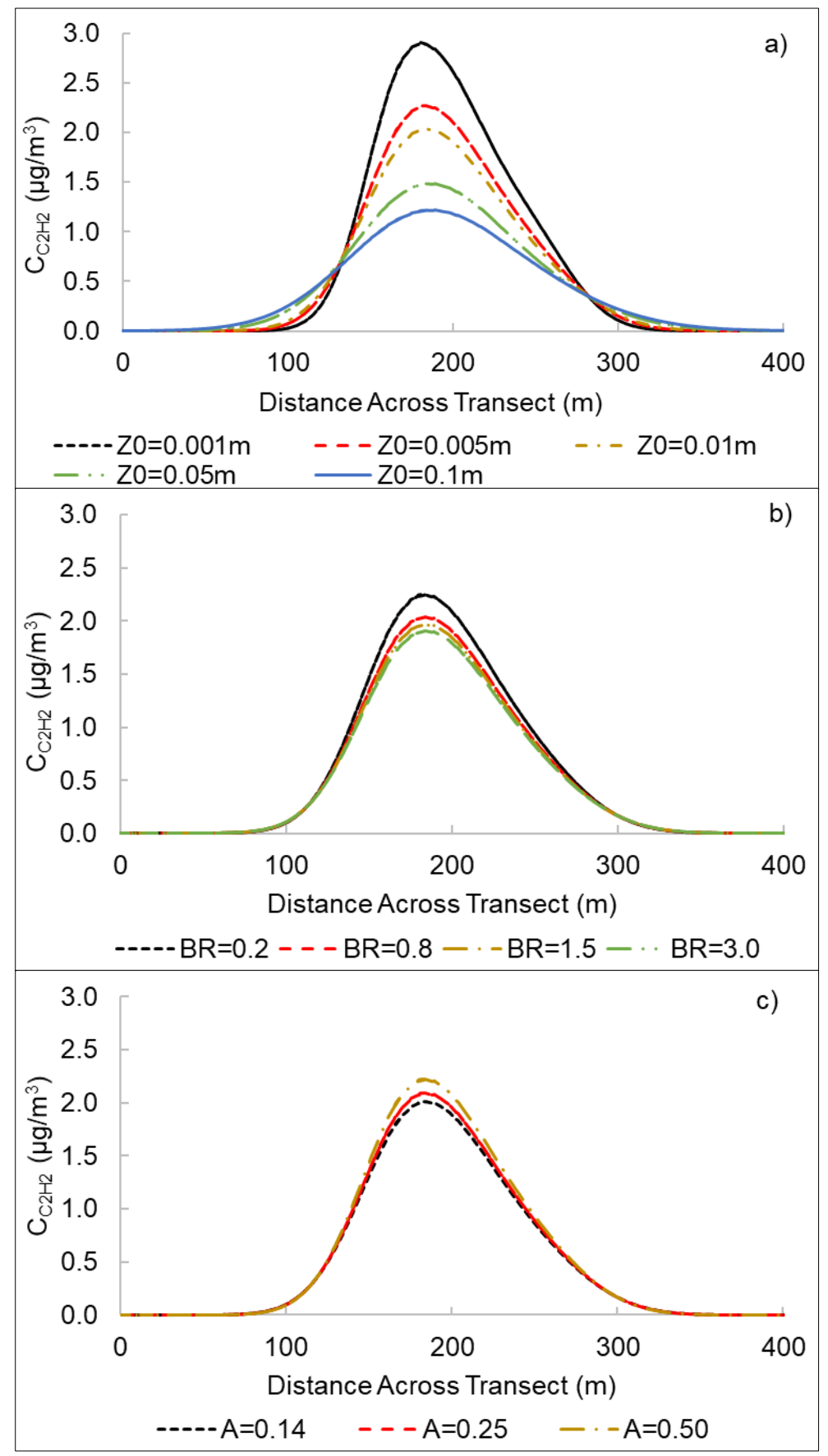

Fig. 3. Sensitivity analysis of AERMOD to a) surface roughness (ZO), b) Bowen ratio (BR) and c) albedo (A) for a transect 2000 meters downwind the reference point and tracer gas $(\mathrm{C} 2 \mathrm{H} 2)$ releases from release points 1,3 and 5 with wind from east and a wind speed of $5 \mathrm{~m} / \mathrm{s}$. Concentrations of acetylene $2 \mathrm{~m}$ above ground level are plotted as a transect perpendicular to the wind direction. 


\subsection{Model calibration and validation}

AERMOD simulations were carried out for three days of the TDM campaign, namely $7^{\text {th }}, 8^{\text {th }}$, and $11^{\text {th }}$ August, hereafter called TDM2, TDM3, and TDM4, respectively. The meteorological conditions varied significantly over the three experiments including the wind direction, providing a wide range of situations against which AERMOD was tested. Different wind directions may be associated with changes in Z0 as the atmospheric boundary layer develops over fetches which may have different effective surface roughness. Fig. 2 shows the average wind direction measured (and used in the simulations) for the three days of the campaign. As a result of the sensitivity analysis discussed above, the calibration of the model was firstly carried out only in terms of finding the value of Z0 that provided the best match between the modelled and measured acetylene plumes. Only acetylene plumes were considered because the release rate and exact location of cylinders were known. Monitoring routes downwind of the landfill are also shown in Fig. 2. In AERMOD, receptors were placed at 2 metres above ground level along the same measured transects with a spacing of $30 \mathrm{~m}$. The positions of the gas cylinders, modelled as individual point sources, are shown in Fig. 1. Table 2 provides a summary of the data from the three tracer releases, giving information about the monitoring roads (transect location), the number and position of the tracer gas cylinders and the associated total acetylene release rate. Atmospheric conditions were slightly stable (negative sensible heat flux, i.e. ground colder than air) during TDM2 and unstable (positive heat flux, i.e. ground warmer than air) for TDM3 and TDM4. The comparison between measured and calculated acetylene concentration data, allowed optimal values of the surface roughness parameter for the three days of the measurement campaign to be obtained. Fig. 4a compares AERMOD's outputs with measured data during TDM2 at a distance of $6700 \mathrm{~m}$. The real data lies between model curves of $\mathrm{Z} 0=0.01 \mathrm{~m}$ and $\mathrm{Z} 0=0.02 \mathrm{~m}$. The lowest residual sum of squares was for $\mathrm{Z0}=0.012$ (29.8) and consequently $\mathrm{Z0}=0.01 \mathrm{~m}$ was selected as an appropriate value for surface roughness. Analogous comparisons with the experimental data pertaining to TDM2 at $2000 \mathrm{~m}$ (not shown) and TDM3 (Fig 4b) also suggest values for $\mathrm{ZO}=0.01 \mathrm{~m}$. The values of $\mathrm{Z} 0$ resulting from the calibration procedure were compared to those suggested by the AERSURFACE User's Guide [EPA, 2013] in order to check their appropriateness. $\mathrm{Z} 0=0.01 \mathrm{~m}$ corresponds to "grassland-type" land covers, which is consistent with the roughness size and the land-use surrounding the study site to the north, south and west (see Fig. 1). It was not possible to obtain a good match between measured and modelled acetylene plumes for TDM4 (Fig 4c). During TDM4 a fresh $9.3 \mathrm{~m} / \mathrm{s}$ wind was from the south-west which together with high heat fluxes contributed to modelled unstable atmospheric conditions with high turbulence. Acetylene cylinders 1, 3 and 4 contributed to the left hand peak in Fig 4c, whereas cylinder 5 was responsible for the right hand peak as confirmed by model simulations carried out with and without cylinder 5 (not shown here). Even assuming the lowest surface roughness value of $\mathrm{Z0}=0.001 \mathrm{~m}$, the model under-predicted the left hand peak by approximately 50\%, although the right hand peak was over-predicted. Both modelled peaks were narrower than the monitoring data. The land-use between the landfill and the monitoring route 1E (Fig. 2) included areas of industrial units and housing, which would tend to increase the average surface roughness. 
Higher surface roughness values would disperse the plume more, which would help achieve a better fit of the width of the modelled plume compared to the monitored, but not with peak height. A reasonable fit of the left hand peak could only be achieved if the modelled wind speed was dropped to $\sim 5 \mathrm{~m} / \mathrm{s}$ and stable atmospheric conditions were assumed. However, these conditions resulted in an exceedingly poor fit for the right hand peak - only if much lower acetylene release rates from cylinder 5 were assumed could the differences be reconciled. Consequently, in the absence of more detailed modelling work we have excluded the modelling results of TDM 4 from the rest of the paper.

Table 2. Overview of data and standard deviations (SD) used in the modelling of TDM.

\begin{tabular}{|c|c|c|c|c|c|c|}
\hline $\begin{array}{l}\text { TDM } \\
\text { Date }\end{array}$ & $\begin{array}{l}\text { Avg. wind direction } \\
\text { [degrees] } \\
\text { (SD) }\end{array}$ & $\begin{array}{l}\text { Avg. wind } \\
\text { speed }[\mathrm{m} / \mathrm{s}] \\
(\mathrm{SD})\end{array}$ & $\begin{array}{c}\text { Heat flux } \\
{\left[\mathrm{W} / \mathrm{m}^{2}\right]}\end{array}$ & $\begin{array}{l}\text { Road, Distance } \\
\text { from the landfill } \\
\qquad[\mathrm{m}]\end{array}$ & $\begin{array}{c}\text { Tracer cylinders } \\
\text { used (refer to } \\
\text { Fig. 1) }\end{array}$ & $\begin{array}{c}\text { Total released } \\
\text { tracer gas rate } \\
{[\mathrm{kg} / \mathrm{h}]}\end{array}$ \\
\hline $\begin{array}{l}\text { TDM2 } \\
7^{\text {th }} \text { Aug }\end{array}$ & $\begin{array}{c}94 \\
(9.4)\end{array}$ & $\begin{array}{c}4.9 \\
(1.3)\end{array}$ & $<0$ & $\begin{array}{l}1 \mathrm{~W}, 2000 \\
3 \mathrm{~W}, 6700\end{array}$ & $1,2,3,5$ & 3.48 \\
\hline $\begin{array}{l}\text { TDM3 } \\
8^{\text {th }} \text { Aug }\end{array}$ & $\begin{array}{l}124 \\
(12)\end{array}$ & $\begin{array}{c}5.1 \\
(1.2)\end{array}$ & 12.5 & $\begin{array}{c}1 \mathrm{~W} / 1 \mathrm{~N}, 1600- \\
2000\end{array}$ & $1,3,5$ & 2.55 \\
\hline $\begin{array}{c}\text { TDM4 } \\
11^{\text {th }} \text { Aug }\end{array}$ & $\begin{array}{l}239 \\
(13)\end{array}$ & $\begin{array}{c}9.3 \\
(1.3)\end{array}$ & 73.5 & $1 \mathrm{E}, 1700-2000$ & $1,3,4,5$ & 2.60 \\
\hline
\end{tabular}




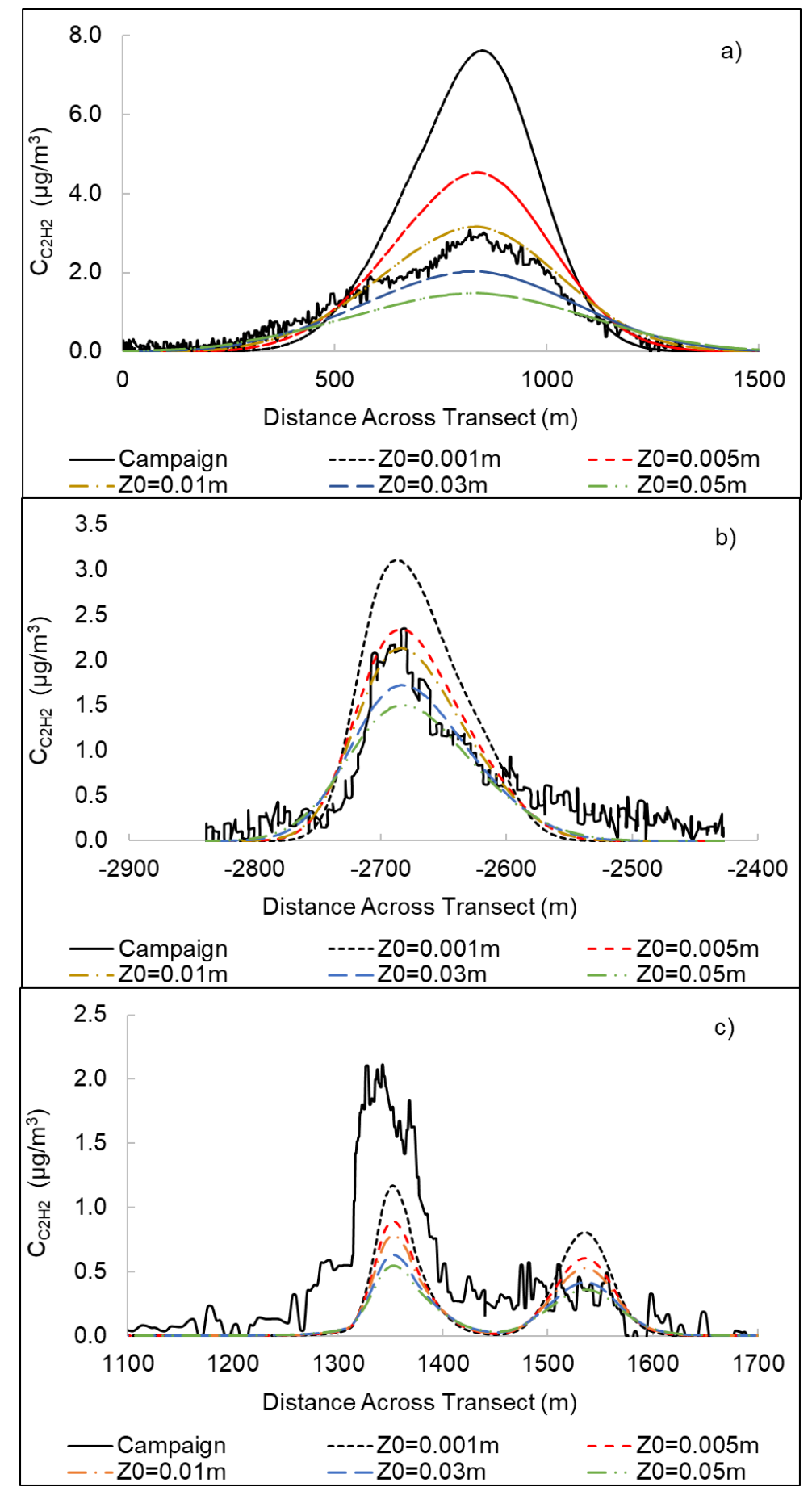

Fig. 4. Measured and calculated acetylene data for a) TDM2 (at a distance of $6700 \mathrm{~m}$ from the landfill), b) TDM 3 (distance $2000 \mathrm{~m}$ ) and c) TDM 4 (distance $2000 \mathrm{~m}$ ).

\subsection{Full mixing distance of tracer and source gas}

Following calibration of the model against Z0, further AERMOD simulations were carried out to establish the distance at which AERMOD predicted full mixing of the tracer and source gas in TDM 2 and TDM3. These simulations were run assuming homogenous emissions of methane from the landfill (as shown in Fig. 2) because no data were available to define its spatial variations. 
Towards this end, it was necessary to define a mixing indicator; RMSD (root mean square deviation - a measure of how well-mixed the gas plumes along a transect are) as follows:

$$
R M S D=\sqrt{\frac{\sum_{i=1}^{N}\left(\frac{C_{C_{4}, i}-C_{C H_{4}, \text { background }}}{C_{C H_{4}, \text { max }}-C_{C H_{4}, \text { background }}}-\frac{C_{t r, i}-C_{t r, \text { background }}}{C_{t r, \text { max }}-C_{t r, \text { background }}}\right)^{2}}{N}}
$$

where $C_{\mathrm{CH}_{4}}, i$ and $C_{t r}, i$ are the measured methane and acetylene concentration at each point of $\mathrm{N}$ receptors along the transect and $C_{C_{4}, \max }$ and $C_{t r \text {,max }}$ are the maximum recorded concentrations along each transect. All concentrations, including background concentrations (e.g. $C_{C H_{4}, \text { background }}$ ), were reported in units of $\mu \mathrm{g} / \mathrm{m}^{3}$.

In a similar approach to that used by Taylor et al. (2016), AERMOD was used to calculate the potential measurement error of a transect.

$$
\text { Error }=\frac{Q_{T D M}-Q_{\text {actual }}}{Q_{\text {actual }}}
$$

where $Q_{T D M}$ is the measured methane emission rate applying equation [1] and $Q_{\text {actual }}$ is the total landfill methane emission rate used in the model.

Using the meteorological conditions associated with the various individual transects measured in the TDMs, AERMOD was used to generate ground level $(+2 \mathrm{~m})$ transects of $\mathrm{C}_{2} \mathrm{H}_{2}$ and $\mathrm{CH}_{4}$ at varying downwind distances from the site using different surface roughness values. Equation 1 was applied to these transects to estimate a methane flux, which was then compared to the known methane flux in the model to calculate a measurement error. Equation 2 was used to produce a RMSD value for each model generated transect, which was plotted against the measurement error in Fig. 5. This indicates that when $R M S D \leq 0.10$ the measurement error was always less than $10 \%$, and consequently we define full-mixing conditions as being satisfied when $R M S D \leq 0.10$. It does not always follow that an RMSD value $>0.10$ will necessarily result in poor measurement error, but values less than 0.10 always resulted in acceptable modelled results. 


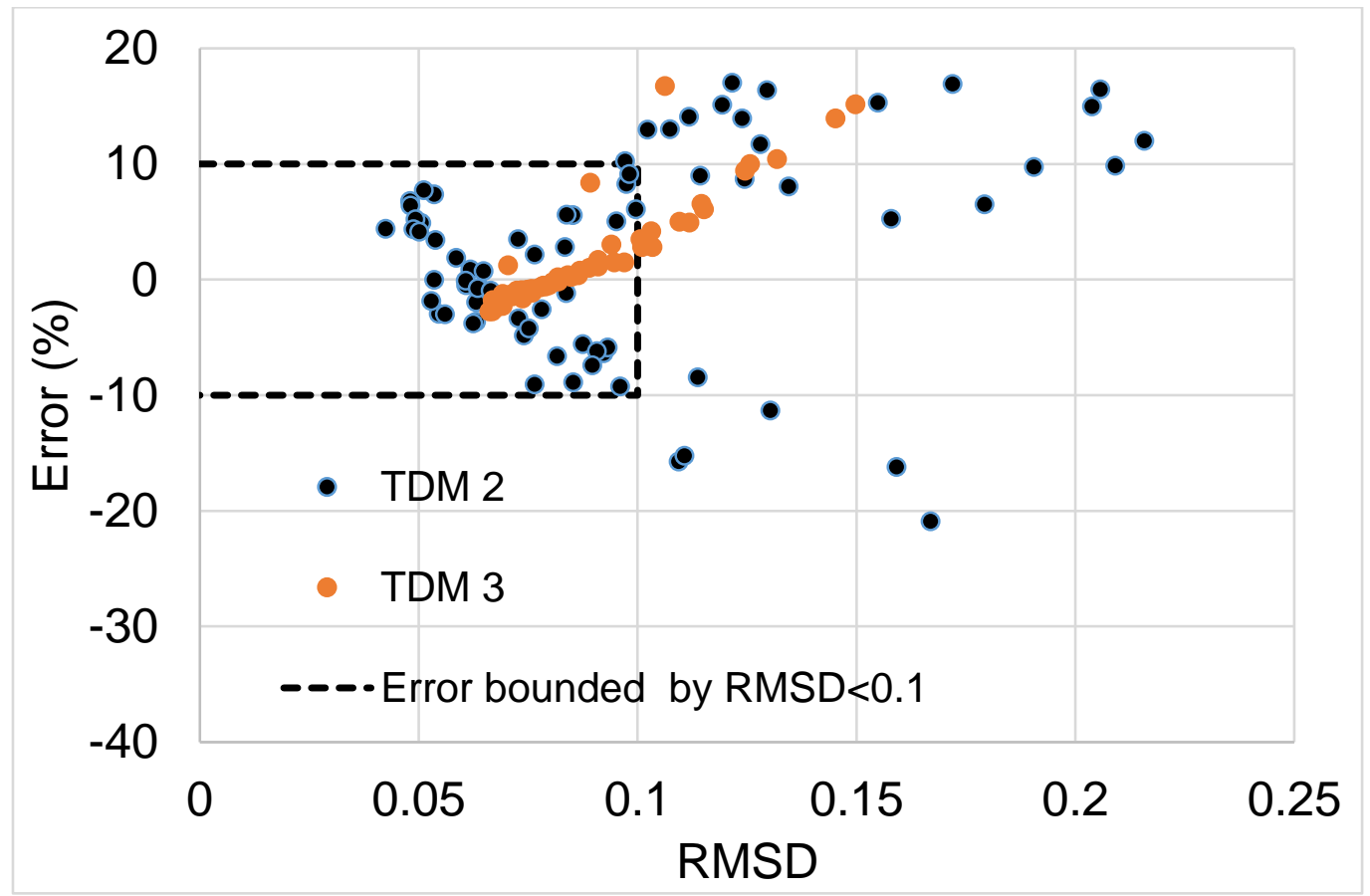

Fig. 5. RMSD versus measurement error in AERMOD simulations.

Foster-Wittig et al., 2015 used the $\mathrm{R}^{2}$ correlation coefficient of a plot of $\mathrm{CH}_{4}$ versus $\mathrm{C}_{2} \mathrm{H}_{2}$ concentrations as an indicator of mixing, rejecting any transects with an $\mathrm{R}^{2}$ value of less than 0.8 . When the same test was applied to transects with an RMSD of $<0.1$, the corresponding $\mathrm{R}^{2}$ value was always greater than 0.8 .

The measurement error was normally positive (i.e. methane estimates from the transects was more than the actual) although some errors, especially for TDM 2 were negative. The possible reasons accounting for error are explored further in section 4.

Fig. 6 shows the RMSD results of the AERMOD simulations for the two different tracer release tests, TDM2 and TDM3; it can be seen that full mixing conditions were achieved at approximately $2600 \mathrm{~m}$ and $2300 \mathrm{~m}$, respectively.

Equation 2 was also applied to the experimental data generated in TDM2 and TDM3 in exactly the same way as for the AERMOD simulations. For each TDM there were a number of different transects, sometimes at different monitoring distances from the landfill. The average RMSD for the different experimental TDMs at different distances are shown on Fig. 6 in comparison to the AERMOD generated values.

The limited experimental data generally matches the AERMOD simulations. RMSD for TDM2 reduces at increasing distances downwind, and the single experimental data point for TDM3 lies on the modelled curve. 


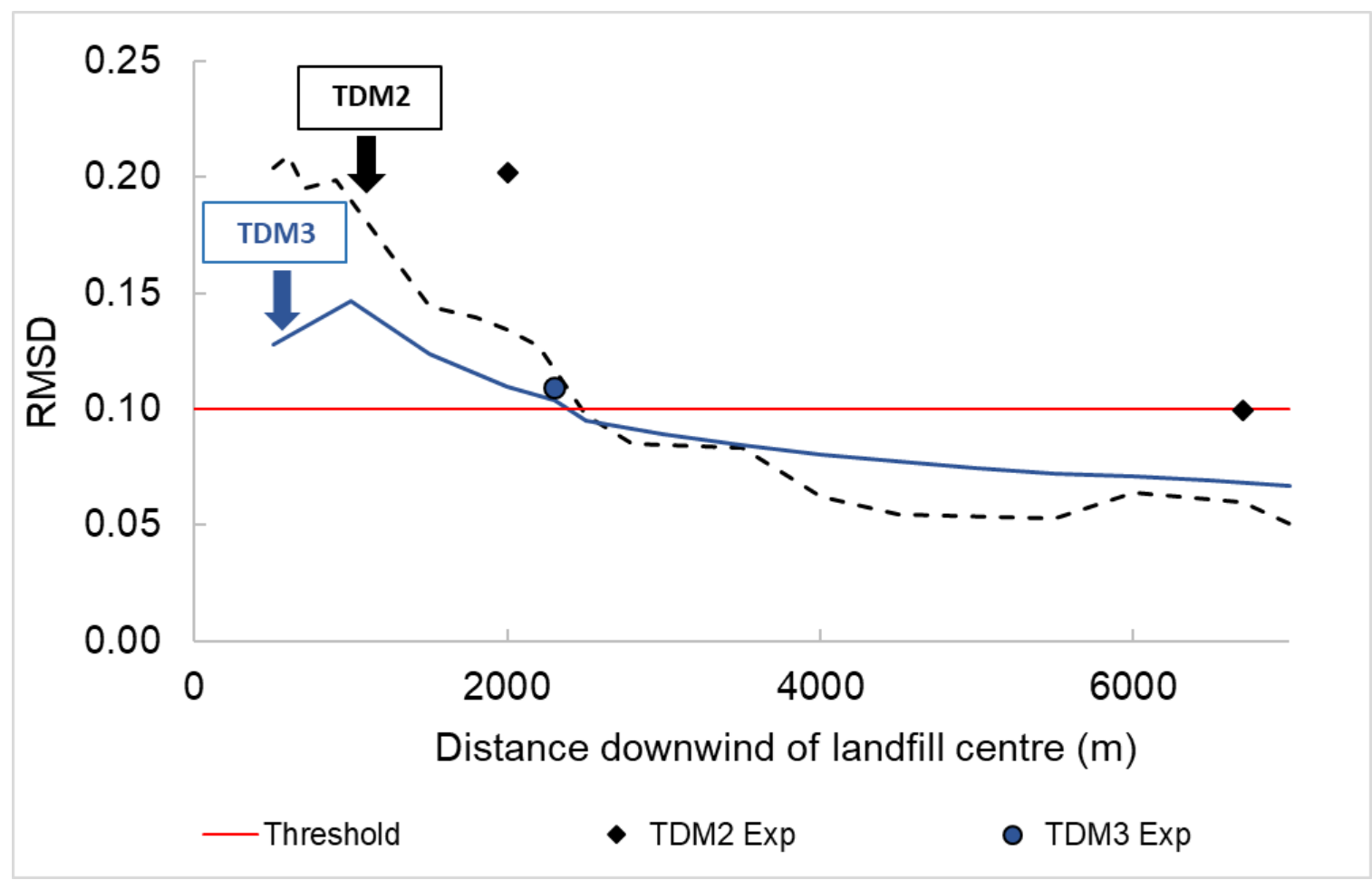

Fig. 6. Trend of the RMSD parameter with the increasing distance from the landfill for the two days of the campaign. Symbols represent the average RMSD value based on the measured concentration transects (TDM2, $2000 \mathrm{~m}$ and $6700 \mathrm{~m}$, TDM3, 2200 $\mathrm{m}$ ) the experimental data, while the lines refer to modelled data. Distance is measured radially from landfill centre, perpendicular to the wind direction.

\section{ANALYSIS AND DISCUSSION}

The calibrated AERMOD model was used as a tool to explore the effect of different meteorological and operational factors on the FMD. This included the effect of mixing conditions over the full height of the Planetary Boundary Layer (PBL), the influence of land-use (terrain), meteorology and the location of different numbers of tracer gas release cylinders. Some of the analyses were derived from simulations of the study site, and others from a more general theoretical approach, but in all instances the interpretation of results is considered by the authors to be applicable to many other landfill sites, especially those in the UK which share similarities with the study site in terms of climatic and topographic conditions.

\subsection{Investigation of full mixing condition above ground level}

The TDM campaigns usually measure the pollutant concentrations at heights of about 2 metres above the ground, without concentration data being collected at higher heights. The use of equation [1] is in principle valid only if the full-mixing condition is satisfied over the entire plume's height, which can vary between 200 and $2000 \mathrm{~m}$ [Collaud Coen et al., 2014]. However, during experiments, full-mixing conditions can only be experimentally checked at ground level. An unanswered question, is whether full mixing conditions measured only at ground level represent acceptable estimates of methane emissions across the full PBL? To answer this question simulations were run to investigate to what extent full vertical mixing can be 
expected over a range of distances from the landfill and with different meteorological conditions. Secondly, simulations were used to investigate the uncertainty associated with methane estimations by means of equation [1], when full mixing conditions were achieved at ground level and not achieved at higher heights.

AERMOD allows the location of receptors to be placed from ground level through the full vertical height of the PBL. Mixing conditions over the entire plume height were investigated for TDM2 and TDM3 by placing receptors at increasing longitudinal distances from the landfill and at different heights above ground surface $(\mathrm{Z})$. RMSD was calculated for transects of plumes at different heights above the ground $(\mathrm{Z}=$ $2-150 \mathrm{~m}$ ). Fig. 7 shows the simulated results associated with TDM2 and TDM3, which demonstrate that the full mixing condition is dependent on measuring height above the ground. This is particularly evident for TDM2 (Fig. 7a), where ground level analysis would suggest a FMD (RMSD $\leq 0.10$ ) is achieved at $\sim 2500 \mathrm{~m}$, whereas at heights more than $75 \mathrm{~m}$, FMD increases to $4000 \mathrm{~m}$. For TDM3 (Fig 7b), the effect is less clear, though still apparent at higher measuring heights. The main difference between TDM 2 and TDM 3 is that stable atmospheric conditions are present in TDM2. It is most likely that the increased turbulence associated with TDM 3 resulted in better vertical and horizontal mixing of the tracer gas and methane plumes.

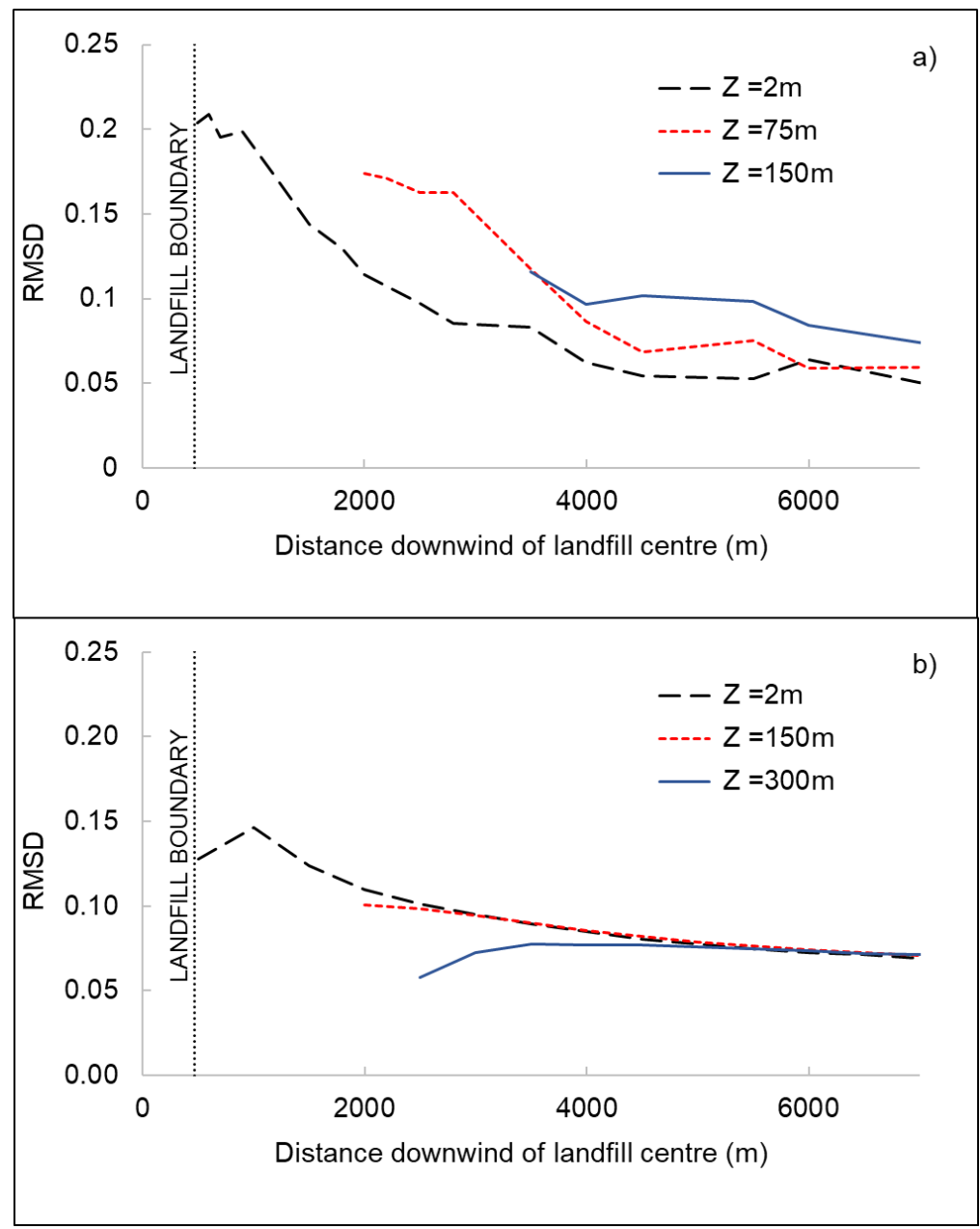

Fig. 7. Trend of RMSD based on simulations at different heights above the ground (Z) for a) TDM2 and b) TDM3. 
The AERMOD calculated measurement error for a ground level generated transect for TDM2 at a distance of 2300 metres was $10.2 \%$ and corresponds to the finding in Fig. 5 that as long as RMSD $<0.10$, measurement errors are at most $\sim 10 \%$. This indicates that incomplete vertical mixing did not unduly affect methane emissions based on ground-level concentration monitoring where full mixing had been achieved.

\subsection{The influence of surface roughness on FMD}

Section 3.1 identified the sensitivity of the model to surface roughness, and calibrated the model to a Z0 value of $0.01 \mathrm{~m}$, which correspond to a grassland land cover. Surface roughness values vary considerably according to land cover namely, from 0.001 for open water to 1.3 for evergreen forest [EPA 2013 ]. Using meteorological and source conditions measured during the TDM campaign, simulations of RMSD as a function of monitoring distance were run by varying $\mathrm{Z} 0$ between $0.002 \mathrm{~m}$ to $1.3 \mathrm{~m}$ and placing receptors at ground level.

Fig. 8 shows results pertaining to TDM3, with similar results obtained for TDM2 (not shown). FMD varies from $<1 \mathrm{~km}$ to $>3 \mathrm{~km}$ downwind of the site depending on Z0. From an operational point of view, it is important to run simulations covering the full range of plausible Z0 values to ensure that monitoring routes for TDM experiments are at distances where full mixing is reached. Ideally this should be based on conservative choices of $\mathrm{Z} 0$ values, but as monitoring route locations are usually restricted, knowing the sensitivity of FMD to Z0 is useful information for the operator.

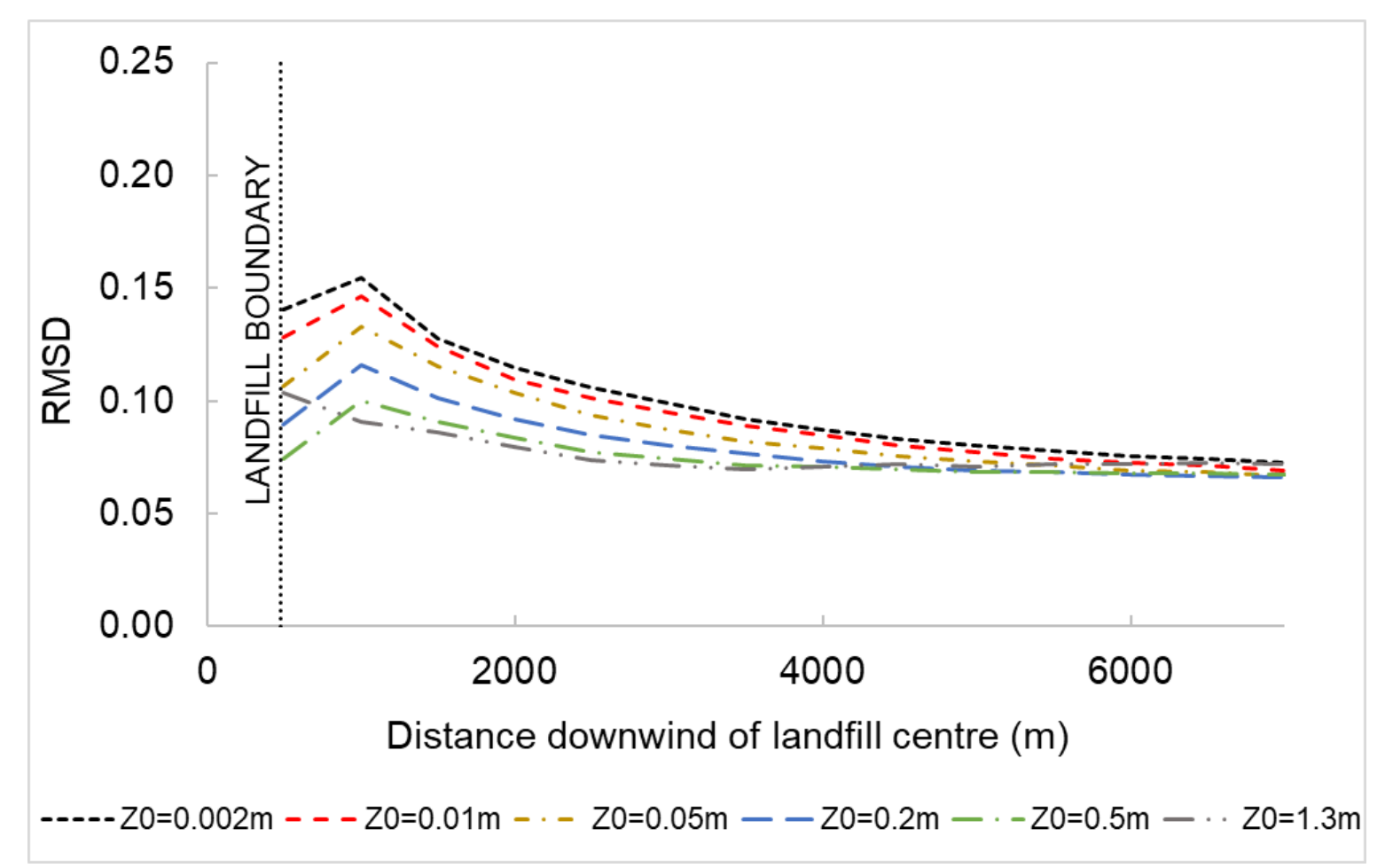

Fig. 8. Trend of the RMSD parameter with the increasing distance from the landfill centre using different surface roughness values based on the meteorological data of TDM3. Receptors are placed at ground level. 


\subsection{The influence of meteorological parameters on FMD}

According to AERMOD's formulation of lateral dispersion [Cimorelli et al., 2004], wind speed and sensible heat flux are the meteorological parameters that have the most influence on lateral dispersion and consequently the FMD. Specifically, wind speed affects the mechanical production of turbulence (i.e. turbulence generated by shear), while the sensible heat flux drives turbulence in its convective form, i.e. turbulence driven by temperature gradients. In AERMOD, both sources of turbulence are lumped into a lateral dispersion parameter that is expressed as follows:

$$
\sigma_{y a}=\frac{\sigma_{v} \cdot x}{u \cdot(1+\alpha X)^{p}}
$$

where $x$ is the distance $(\mathrm{m})$ from the source, $u$ is the wind speed $(\mathrm{m} / \mathrm{s})$ along the longitudinal direction, $\alpha=78$ and $p=0.3$ are two free parameters that are set as constants. $X$ is a dimensionless term, which accounts for lateral turbulence intensity $\sigma_{v}(\mathrm{~m} / \mathrm{s})$ :

$$
X=\frac{\sigma_{v} \cdot x}{u \cdot z_{i}}
$$

where $z_{i}$ is the mixing height $(\mathrm{m})$, defined as the highest value between the mechanical and convective mixing heights. The lateral turbulence intensity is calculated using:

$$
\sigma_{v}^{2}=\sigma_{v c}^{2}+\sigma_{v m}^{2}[4]
$$

where $\sigma_{v c}^{2}=0.35 \cdot w_{*}^{2}$ and $\sigma_{v m}^{2}=\left[\frac{\sigma_{v m}^{2}\left\{z_{i m}\right\}-\sigma_{v 0}^{2}}{z_{i m}}\right] z+\sigma_{v 0}^{2}$ are respectively the convective and mechanical turbulence component $\left(\mathrm{m}^{2} / \mathrm{s}^{2}\right) \cdot w_{*}$ is the convective velocity scale $(\mathrm{m} / \mathrm{s})$ and $\sigma_{v 0}^{2}=C \cdot u_{*}^{2}$, where $\mathrm{C}$ ranges between 3 and 5 and $u_{*}$ is the friction velocity $(\mathrm{m} / \mathrm{s})$. Finally, $\sigma_{v m}^{2}\left\{z_{i m}\right\}=M I N\left[\sigma_{v 0}^{2} ; 0.25 m^{2} / s^{2}\right]$.

Simulations were carried out using a range of heat flux $(\mathrm{H})$ and wind speed combinations (Table 3), Z0 was fixed at $0.01 \mathrm{~m}$ and the wind direction from the east. Receptors were placed at increasing distances from the landfill, 2 metres above the ground. The results of the simulations are shown in Fig 9. It is clear that the influence of the heat flux on the FMD decreases with increasing wind speed. For velocities greater than 15 $\mathrm{m} / \mathrm{s}$, the heat flux does not influence the FMD. The least favourable conditions are those associated with a wind speed $<3 \mathrm{~m} / \mathrm{s}$ and a sensible heat flux $<30 \mathrm{~W} / \mathrm{m}^{2}$, where both mechanical and convective turbulence are very low. These conditions lead to the largest distances $(\sim 4 \mathrm{~km})$ before full mixing conditions are achieved.

Interestingly, the model indicates low FMDs for low wind speed and (high) positive heat fluxes. However, these results must be viewed with caution, and may reflect a limitation of AERMOD. Experience 
of running TDM campaigns (Rees-White et al., 2018) indicates plumes are often not detected at ground level during periods of high heat flux (e.g. middle of summer days) as strong convective forces rapidly transport the gases to high heights.

Overall the simulations suggest that the FMD decreases for increasing wind speed and this is reasonable because higher wind speeds cause greater (mechanical) turbulence and, ultimately, lateral dispersion. This trend is generally valid except for wind speeds lower than $4 \mathrm{~m} / \mathrm{s}$ and sensible heat fluxes greater than 30 $\mathrm{W} / \mathrm{m}^{2}$ whereby Fig. 9 shows an increasing trend of FMD with increasing wind speed. It is suggested that this rather counter-intuitive result is associated with how the lateral dispersion parameter depends on the velocity $u$ in equation [3]. Whether this trend reflects real physics is something that goes beyond the scope of this paper and should be investigated further.

Table 3: Wind speed and heat flux values used in the AERMOD simulations to evaluate the influence of meteorological parameters on full mixing distance.

\begin{tabular}{|l|c|c|c|c|c|}
\hline Wind Speed $[\mathrm{m} / \mathrm{s}]$ & 2 & 5 & 10 & 15 & 20 \\
\hline Heat Flux $\left[\mathrm{W} / \mathrm{m}^{2}\right]$ & $<0$ & 10 & 30 & 75 & 150 \\
\hline
\end{tabular}

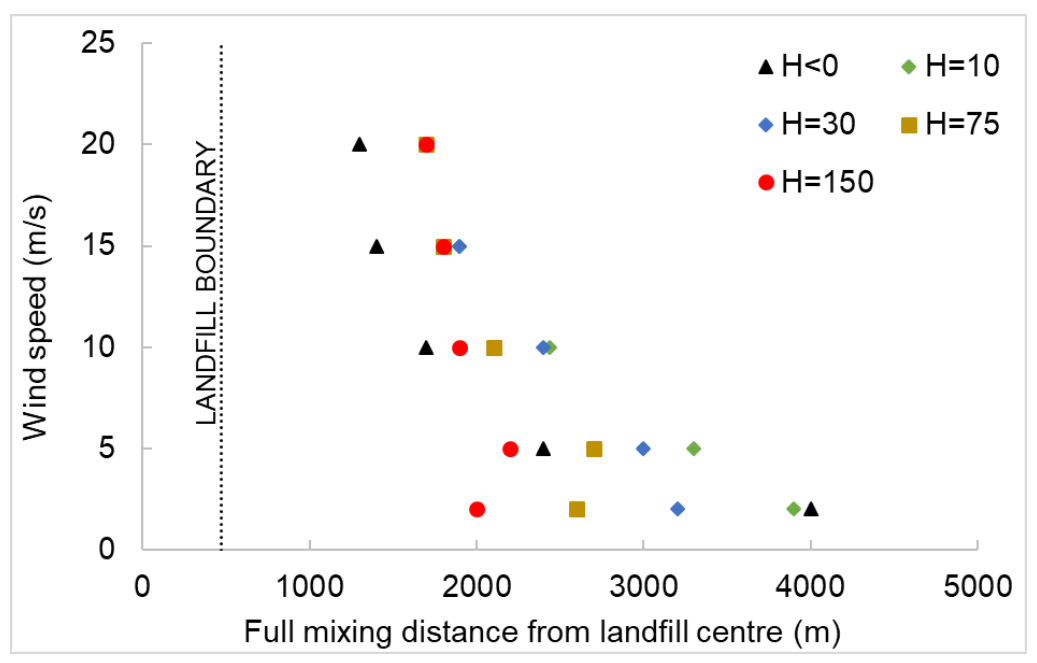

Fig. 9. Full mixing distance (FMD) from the landfill centre with varying wind speed and heat flux; $H\left(W / m^{2}\right)$.

Fig. 9 suggests that high wind velocities may be desirable in tracer gas experiments, as they contribute to a decrease in the FMD. However, tracer gas dilution should also be taken into consideration. Fig. 10 shows acetylene peak concentrations at increasing distances from the landfill, obtained from simulations where the sensible heat flux was fixed at $\mathrm{H}=10 \mathrm{~W} / \mathrm{m}^{2}$ and the wind speed varied from $5 \mathrm{~m} / \mathrm{s}$ to $15 \mathrm{~m} / \mathrm{s}$. The threshold line identifies the detection limit a typical cavity ring down (CRD) analyser for acetylene (0.4 ppb $\left.=0.46 \mu \mathrm{g} / \mathrm{m}^{3}\right)$ such as the one used in the experimental trials. Fig. 10 shows that the more the wind speed increases, the more the tracer gas is diluted and the sooner the plume becomes undetectable by the instrumentation. This means that ideal velocities should allow for short FMDs as well as avoiding excessive 
dilution. As a simple rule of thumb, it was observed that wind velocities within the range of 4-8 $\mathrm{m} / \mathrm{s}$ may satisfy this trade-off. This agrees with Foster-Wittig et al. (2015) who concluded that best results were achieved from the tracer gas dispersion method under "moderate" wind speeds, less than $10 \mathrm{~m} / \mathrm{s}$.

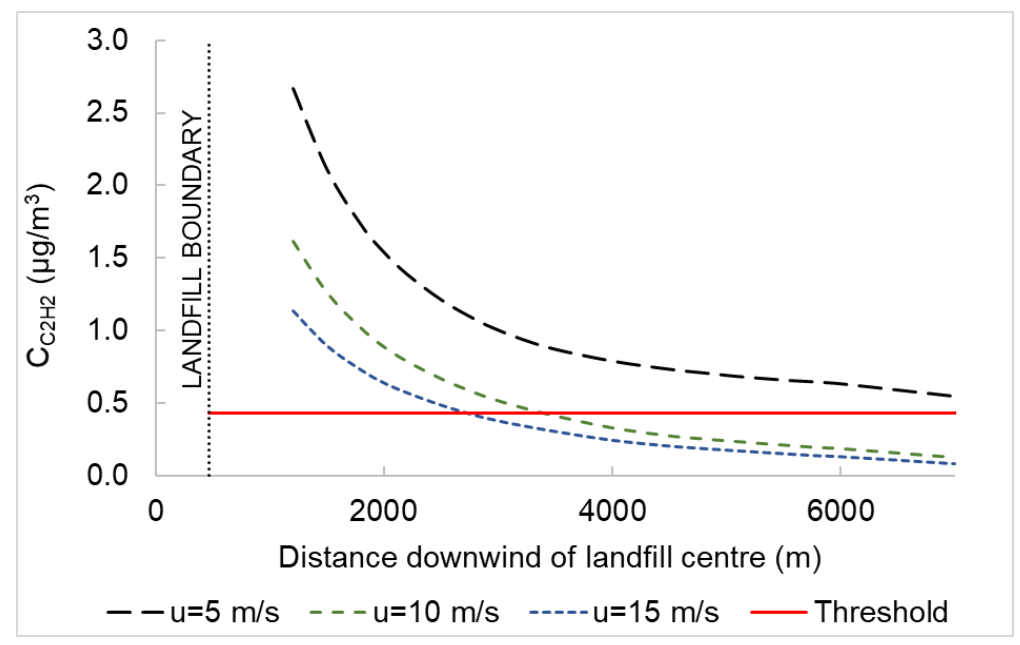

Fig. 10: Acetylene peak concentrations at increasing distance from the landfill centre and with varying wind speed. The heat flux is fixed to $10 \mathrm{~W} / \mathrm{m}^{2}$. The threshold represents the detection limit of a typical CRD acetylene analyser ( $\left.0.40 \mathrm{ppb}\right)$.

\subsection{The influence of tracer cylinder placement and wind direction on measurement error and FMD}

The optimum number and correct placement of tracer gas cylinders on the landfill surface is key to accurate TDMs. How these two variables influence the RMSD and measurement errors (and ultimately, the quality of TDMs) is not yet clear (Taylor et al. 2016). In order to investigate this issue a large number of simulations were undertaken by varying the number of cylinders, their positioning within the landfill and the wind direction. Wind speed, heat flux and surface roughness were kept constant at $5 \mathrm{~m} / \mathrm{s}, 30 \mathrm{~W} / \mathrm{m}^{2}$ and 0.01 $\mathrm{m}$, respectively. These are realistic values as observed during the experimental campaign and from the model calibration procedure (section 3.2). In agreement with the results of Taylor et al. (2016) and Mønster et al. (2014), the simulations confirmed that cylinders placed close to the centre of a landfill result in the lowest measurement errors at different distances downwind. Fig. 11, as an example, displays results from simulations with the wind from the south and three acetylene tracer gas cylinders positioned in five different configurations. In this case, configuration 5 (best reflecting the centre of the landfill when the irregular topology is taken into account) resulted in the lowest measurement error. It was also observed that tracer gas cylinders placed downwind of the centre of the site (configuration 3) resulted in under estimation of methane emissions at monitoring distances up to $4 \mathrm{~km}$ from the site, whereas gas cylinders on the upwind side of the site (configuration 1) significantly overestimated emissions. Finally, it is worth noting that configurations characterised by small measurement errors are not necessarily associated with low RMSD values.

Although the agreement with the literature is encouraging, it is not clear to what extent the results obtained from these simulations can be considered of general validity because of the site-specific landfill 
conditions including geometry, methane emission pattern, topography, and meteorological and roughness conditions. It was therefore decided that further insights could be obtained by performing idealised simulations of a circular and homogeneous landfill in flat terrain, which rules out the effects landfill geometry and topography. Meteorological (and roughness) conditions as well as number and placement of tracer gas cylinders were extensively varied in order to identify (i) the appropriate number of cylinders to be used for a given landfill size, and (ii) to better understand how cylinders' placement and number influence RMSD and measurement error of TDMs.

a)
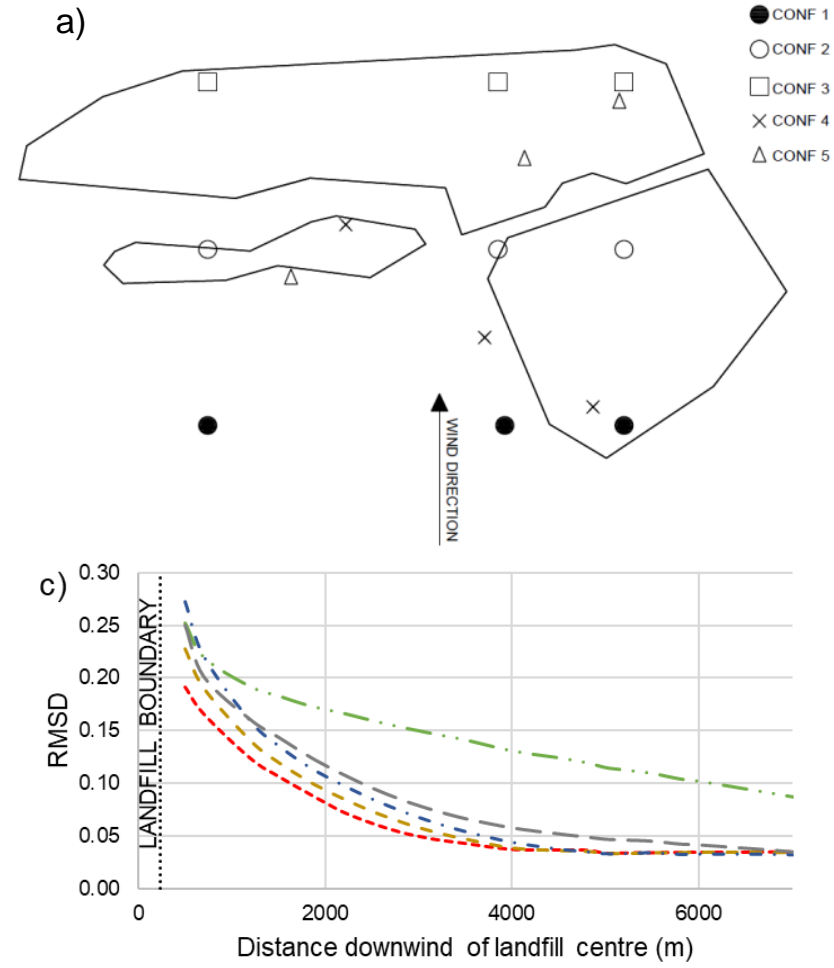

$----\operatorname{CONF} 1---\operatorname{CONF} 2-\cdots \operatorname{CONF} 3-\cdots \operatorname{CONF} 4--\operatorname{CONF} 5$

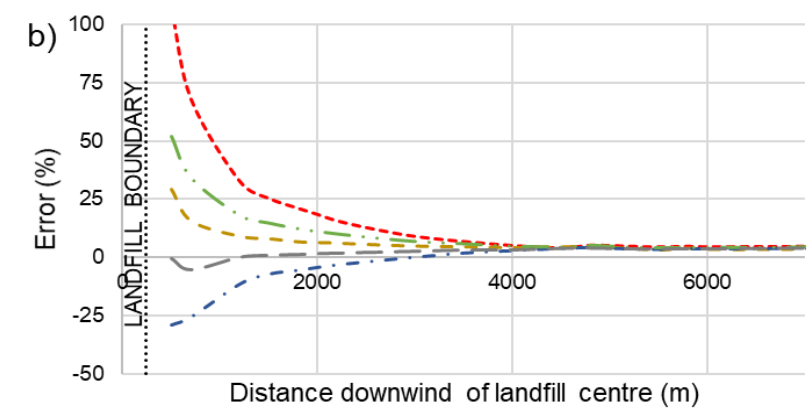

--- CONF $1---$ CONF $2-\cdots$ CONF $3-\cdots$ CONF $4--$ CONF 5

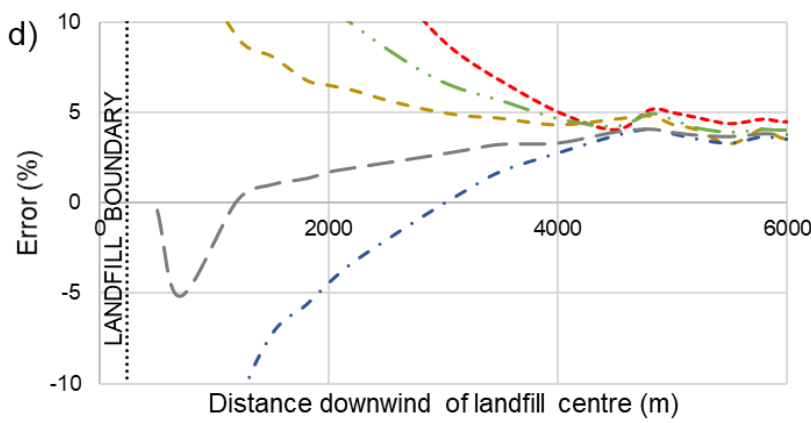

CONF $1---\operatorname{CONF} 2-\cdot-\operatorname{CONF} 3-\cdots \operatorname{coNF} 4--\operatorname{CONF} 5$

Fig. 11. a) Tracer configurations using three tracer gas cylinders with wind from the south; b) Measurement error; c) RMSD; d) Measurement error with y-axis zoomed to show detail.

The landfill was modelled as a circular area within a flat terrain and its radius (R) was incrementally increased from 100 up to 750 metres. We compared meteorological and terrain parameters that led to very good mixing of tracer gas and methane (wind speed, heat flux and surface roughness equal to $8 \mathrm{~m} / \mathrm{s}, 45$ $\mathrm{W} / \mathrm{m}^{2}$ and 0.1 metres respectively) with conditions that led to poor mixing (wind speed, heat flux and surface roughness equal to $4 \mathrm{~m} / \mathrm{s}, 15 \mathrm{~W} / \mathrm{m}^{2}$ and 0.01 metres respectively). Fig. 12 shows the results obtained using one gas cylinder placed centrally in the idealised landfill. When downwind monitoring distance is normalised against landfill radius all plots of measurement error for different landfill sizes are closely bounded (Fig 12b). The effect of meteorological conditions that encourage good versus bad mixing has little impact on measurement error (Fig. 12b), although mixing strongly affects RMSD (Fig. 12a). For the specific conditions 
modelled, which includes an aerially homogeneous emission area, if measurement errors are to be constrained within $10 \%$ then the monitoring distance downwind should be approximately 2.5 times the landfill radius; for errors less than $\sim 5 \%$ the downwind monitoring distance should be approximately 3.5 times the landfill radius. Further modelling is required to test the validity of this conclusion for other combinations of meteorological conditions, and heterogeneity in surface roughness values and emissions.
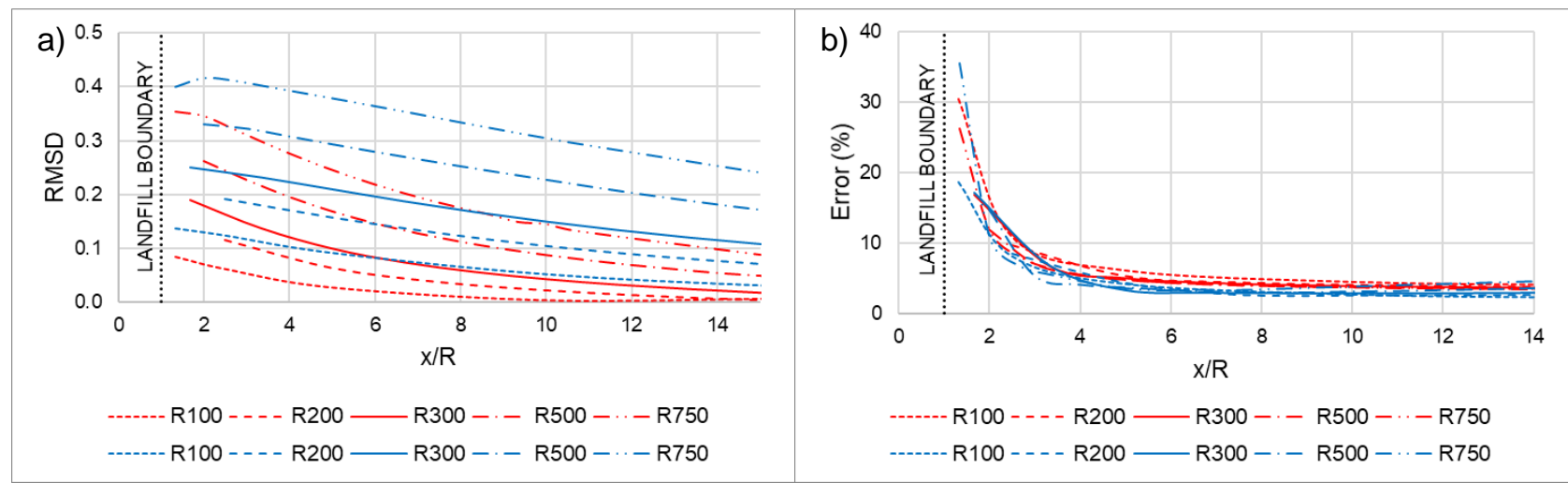

Fig. 12. a) RMSD and measurement error b) with ratio of distance downwind ( $x$ ) to landfill radius (R). One cylinder release point is placed in the landfill centre. The red and blue lines refer to meteorological conditions that encourage and discourage full mixing, respectively.

Fig. 13 shows the RMSD trend when the landfill radius is fixed at 750 metres (approximately the average dimensions of the study site) and the number of tracer release points is increased from 1 through to 4. The analysis indicates that increasing the number of gas cylinders perpendicular to the wind direction has no influence on measurement error (Fig 13b), although it has a major impact on RMSD (Fig 13a). The explanation for this is that the TDM method requires that both tracer and source gas disperse, both laterally and vertically, in a similar manner in a downwind direction. This is usually interpreted as requiring that source and tracer gas plume transects match, which is a sufficient but not a necessary requirement. Consider the case of a single point source of methane co-located with a point source of tracer gas emitting at a different rate. At all locations downwind the source gas and tracer gas will have dispersed in exactly the same manner, and theoretically the application of the TDM technique would result in identically shaped normalised plume transects (i.e. $\mathrm{RMSD}=0$ ) and zero measurement error. If, in this theoretical situation, the tracer gas is moved perpendicular to the wind direction and if it is further assumed that the manner in which the tracer gas disperses does not change, then the tracer gas plume will continue to give zero error as long as it is measured at exactly the same distance downwind as the source plume. The plumes do not even have to overlap, a situation which would result in $\mathrm{RMSD}=1$.

Previous TDM campaigns have tended to locate tracer release cylinders as close to the areas assumed to be emitting methane as practically possible. The ideal location for a single tracer gas release point is in the centre of an emitting area. Where more than one cylinder is used and in the case of aerially distributed and homogenous methane sources (as modelled here), Fig 13c and Fig 13d, show that increasing the number of 
cylinders parallel to the wind direction may result in lower measurement error at locations close to the landfill. However, there is little benefit of using more than one tracer gas release point if monitoring is undertaken at distances greater than $2500 \mathrm{~m}$ downwind. The RMSD value associated with cylinders placed parallel to the wind is independent of the number of cylinders used.

Fig. 14 investigates the relationship between wind direction and measurement error for different numbers of tracer gas cylinders. We report the downwind TDM monitoring distance for a $750 \mathrm{~m}$ radius landfill at which measurement error is $10 \%$. The modelled conditions were wind speed $5.5 \mathrm{~m} / \mathrm{s}$, heat flux 15 $\mathrm{W} / \mathrm{m}^{2}$, and surface roughness $0.01 \mathrm{~m}$. As reported above, when the wind direction is perpendicular $\left(90^{\circ}\right)$ to the line of cylinders, the measurement error (at a given downwind distance) is independent of the number of gas cylinders. This effect occurs at wind directions between $75^{\circ}$ and $90^{\circ}$. At a wind direction between $\sim 45^{\circ}$ and $60^{\circ}$ an improvement in measurement error occurs if the number of cylinders is increased from one however, there is no difference whether two, three or four cylinders are used. When wind direction is between $0^{\circ}$ (parallel) and $\sim 30^{\circ}$ then four gas cylinders provide the lowest measurement errors: two or three gas cylinders provide similar results. 

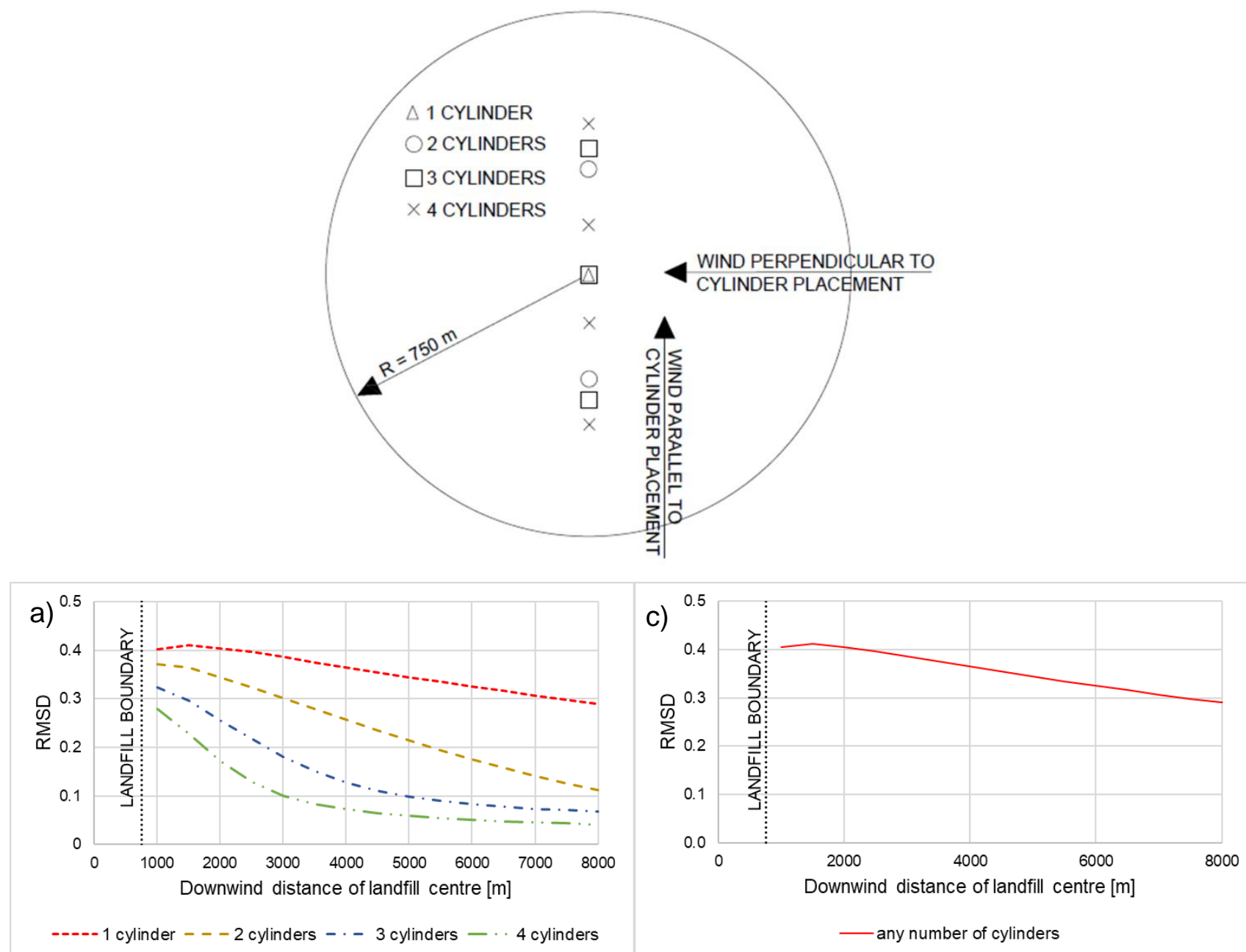

- any number of cylinders
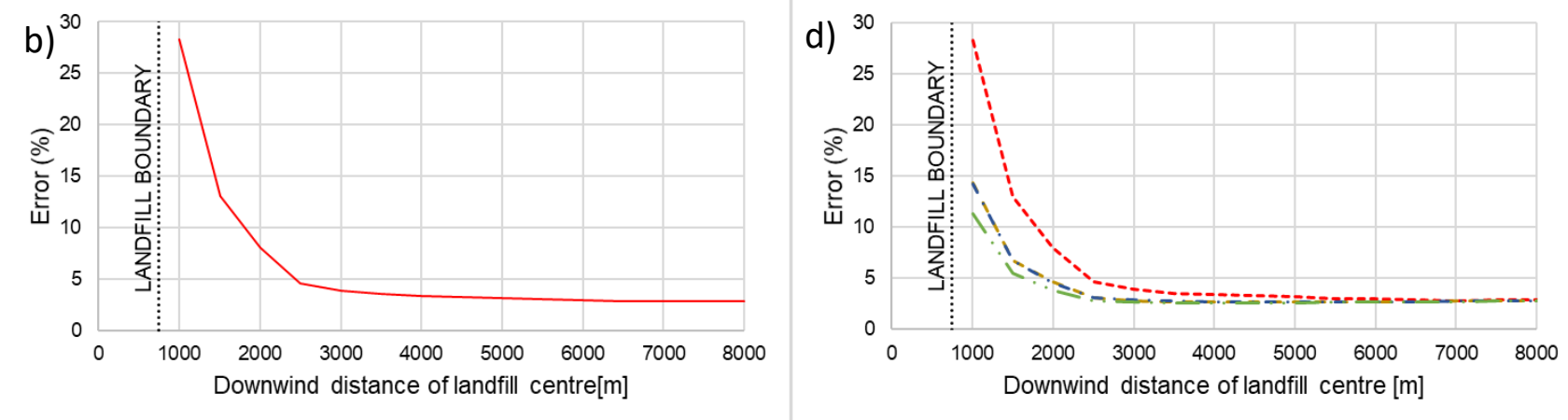

_ any number of cylinders

---- 1 cylinder - - -2 cylinders - - 3 cylinders - - 4 cylinders

Fig. 13. Trend of the RMSD parameter and measurement error for a) and b) wind perpendicular to, and c) and d) wind parallel to cylinder orientation. The landfill radius is $750 \mathrm{~m}$. The wind speed and the heat flux are $5.5 \mathrm{~m} / \mathrm{s}$ and $15 \mathrm{~W} / \mathrm{m}^{2}$, respectively. 

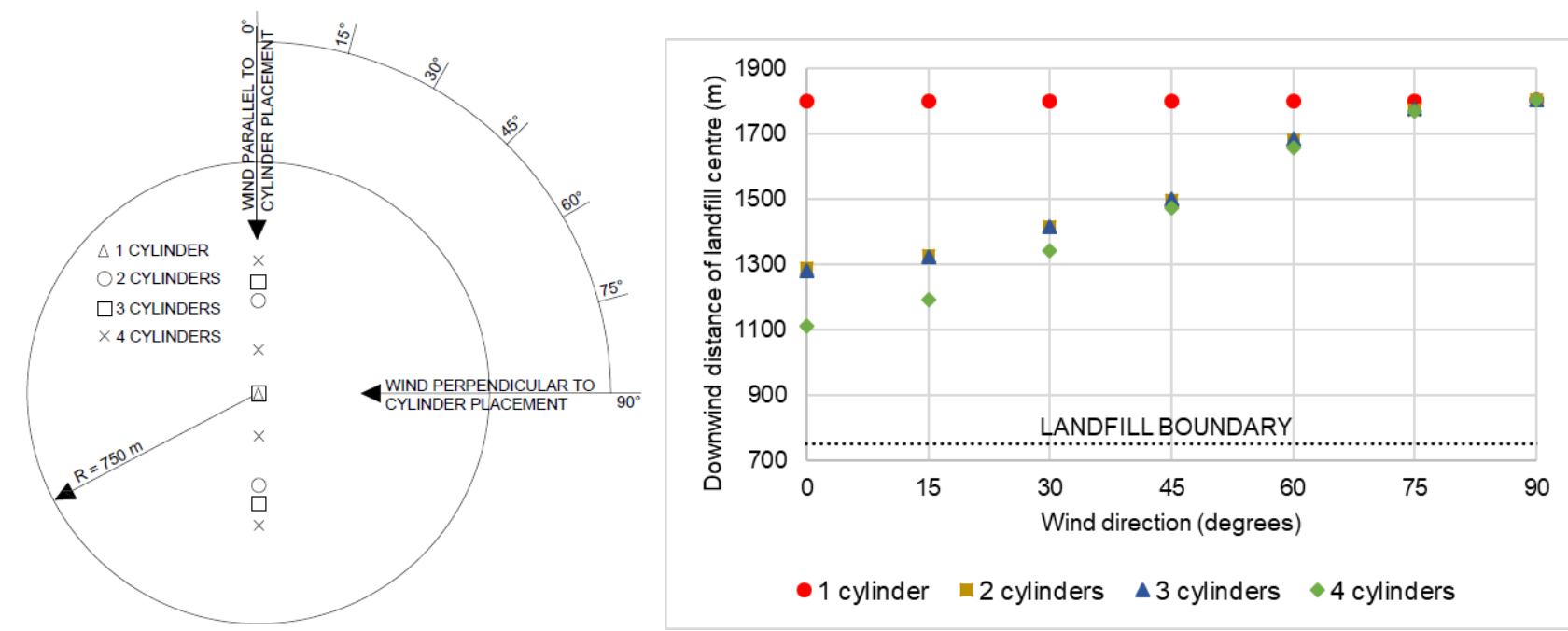

Fig. 14. Monitoring distance where measurement error is $10 \%$ considering 1 to 4 gas cylinders and wind direction varying from $0^{\circ}$ to $90^{\circ}$. The landfill radius is $750 \mathrm{~m}$. The wind speed, heat flux and surface roughness are $5.5 \mathrm{~m} / \mathrm{s}, 15 \mathrm{~W} / \mathrm{m}^{2}$ and $0.01 \mathrm{~m}$, respectively.

\subsection{The use of Gaussian dispersion models for planning and analysing tracer gas dispersion tests}

The ability to use downwind plumes of the known release of tracer gas to calibrate Gaussian dispersion models that includes topography, like AERMOD, provides a valuable tool to help analyse the results of TDM surveys on landfills. In this study, where the surrounding land-use was grassland (or crops) this approach worked very well. It was not successful when the wind direction meant that the plumes were passing over industrial and residential areas, but this does not mean that this is a general exception additional work is required to investigate this further.

A pre-configured AERMOD type model with reasonable estimates of roughness coefficients allows preplanning of TDM tests to be undertaken, for a range of wind speeds, wind directions and in stable and unstable meteorological conditions. A desk-study of the surrounding land-use (e.g. through satellite imagery) would allow approximate roughness coefficients (Z0) depending on wind direction to be estimated. This could then be verified by on-site acetylene releases. In particular, the number and placement of tracer cylinders can be investigated to provide an indication of how far downwind monitoring needs to be undertaken for full-mixing conditions to be established. The nature of the emission source is of course an unknown model variable, but by considering a variety of extreme emission behaviours, (e.g. homogenous emissions and/or a small number of hotspots) then insights can still be learned, measurement error can potentially be bounded and a relationship between RMSD and measurement error established.

Although RMSD is not an absolute indicator of whether a low measurement error can be achieved, low RMSD does usually lead to low measurement error. As a tool to the user it has the advantage that it is a parameter that could be calculated in real time as TDM surveys are being undertaken. If prior modelling has given the operator an understanding of the relationship between RMSD and error for different cylinder 
positions and a range of wind speeds, then it could potentially become a very useful tool to help run campaigns to minimise error.

The speed of running Gaussian models also creates the possibility that a pre-configured model could allow some on-site analysis of data during a monitoring campaign, which could positively influence decisions about the ongoing planning of TDM tests.

\section{CONCLUSIONS AND FUTURE WORK}

The Gaussian model AERMOD was used to investigate the possibility of using simple atmospheric dispersion models to support TDM campaigns. A sensitivity analysis indicated that surface roughness has the most significant influence on the calibration of the model. Calibration of the model against field data indicated that AERMOD's default surface roughness values for a land-use of grass, which matched the landuse surrounding much of the site, were applicable and provided a good match between experimental and modelled results. This provides confidence that, for planning purposes, a desk study that identifies the surrounding land-use will help configure the model appropriately. The results show that measured acetylene concentrations can be used to further calibrate the model.

The calibrated model was used to evaluate the actual TDM campaigns carried out, which involved a number of different tracer gas release points within the curtilage of the landfill and different meteorological conditions over a number of days. A uniform aerially distributed methane release was assumed and transects of tracer gas and methane produced at varying downwind distances at 2 metres above ground level, where a typical measurement campaign would be performed. RMSD was used as an indicator of the degree to which acetylene tracer gas and methane plumes were well-mixed, with mixing increasing the further downwind the plumes have travelled. Full mixing conditions are defined when RMSD $<0.10$, which occurred at full mixing distance (FMD) downwind of the site. The measurement error associated with plumes that were fully mixed (RMSD < 0.10) were always less than $10 \%$ for the site modelled.

The calibrated model was used to investigate mixing conditions across the entire plume height for the actual TDM campaigns carried out. It was observed that full mixing conditions at ground level do not imply full mixing over the entire plume height. However, when full mixing conditions were satisfied at ground level, then the error introduced by variations in mixing higher up were always less than $10 \%$.

The influence of meteorological and terrain parameters on FMD was investigated, considering a wide range of roughness length, wind speed and sensible heat flux values. Simulations demonstrated that surface roughness highly influences the FMD. High surface roughness values encourage mechanical turbulence and lateral dispersion, reducing the full mixing distance. Furthermore, although the model suggests that high values of wind speed and heat flux reduce the FMD, these meteorological conditions can cause excessive dilution. Low wind speeds are also not favourable for TDM campaigns as they are associated with large values of FMD. The modelling indicated an optimal wind speed for TDM campaigns of between $\sim 4-8 \mathrm{~m} / \mathrm{s}$. The influence of the number and placement of tracer gas cylinders on measurement error and FMD was 
investigated. The Gaussian model AERMOD replicated the results of others that measurement error was lowest when tracer was released from the centre of an emitting area when assuming homogenous methane emissions. A theoretical study of a circular landfill with homogenous emission of methane indicated that the distance downwind at which monitoring should be undertaken was approximately 2.5 times the landfill radius to achieve measurement errors less than $\sim 10 \%$ and 3.5 times the landfill radius for measurement errors less than $\sim 5 \%$. There was little difference in measurement error between meteorological conditions that encouraged good atmospheric mixing and those that resulted in poor mixing. Further work is required to tests the general applicability of this finding.

In terms of measurement error, there was no difference whether tracer gas was released from a single point in the middle of the theoretical circular site, or from a line of gas cylinders across the middle of the site perpendicular to the wind direction. However, increasing the number of cylinders parallel to the wind direction resulted in lower errors. This is presumably a result of a better representation of the source along the longitudinal direction, which creates a distribution of tracer fetches downwind that better reflects the true distribution of fetches of the source plume. There was a strong correlation between wind direction relative to the number and orientation of a line of tracer gas cylinders. This finding has potential implications on the running of TDM surveys, although further modelling work is required to understand how this relates to emissions that are more heterogeneous.

RMSD is not an absolute indicator of whether a low measurement error can be achieved, although low RMSD values do usually lead to low measurement error. RMSD is a parameter that could be calculated in real time as TDM surveys are being undertaken, and is potentially a useful tool during monitoring campaigns to help minimise measurement errors. This is especially true if the operator has developed an understanding of the relationship between different tracer release positions and a range of wind / directions from prior modelling.

The results of this research relate to a single experimental study site, but the results are applicable to other sites. Future works will focus on analysing the landfill emission heterogeneity and the possibility to use simple models to consider a large number of scenarios, helping further TDM campaigns.

\section{AKNOWLEDGEMENTS}

This work was supported by EPSRC platform grant: 'Processes, mechanics \& management of residual wastes' (EPSRC GR/T25194/01). This study included re-analysis of data produced by the Technical University of Denmark. Summary data supporting this paper are openly available from the University of Southampton repository at http://doi.org/10.5258/SOTON/D0391.

\section{REFERENCES}

Abichou, T., Chanton, J., Powelson, D., Fleiger, J., Escoriaza, S., Lei, Y., \& Stern, J. (2006). Methane flux and oxidation at two types of intermediate landfill covers. Waste Management, 26(11), 1305-1312. 
Babilotte, A., Lagier, T., Fiani, E., \& Taramini, V. (2010). Fugitive Methane Emissions from Landfills: Field Comparison of Five Methods on a French Landfill. Journal of Environmental Engineering, 136(8), 777-784.

Börjesson, G., Samuelsson, J., Chanton, J., Adolfsson, R., Galle, B., \& Svensson, B. H. (2009). A national landfill methane budget for Sweden based on field measurements, and an evaluation of IPCC models. Tellus, Series B: Chemical and Physical Meteorology, 61 B(2), 424-435.

Chan, A. S. K., Prueger, J. H., \& Parkin, T. B. (1998). Comparison of Closed-Chamber and Bowen-Ratio Methods for Determining Methane Flux from Peatland Surfaces. J. Environ. Qual., 27(1), 232-239.

Cimorelli, A. J., Perry, S. G., Venkatram, A., Weil, J. C., Paine, R. J., Wilson, R. B., .. Paumier, J. O. (2004). AERMOD: Description of model formulation. Report, 44(July 2015), 1-91.

Collaud Coen, M., Praz, C., Haefele, A., Ruffieux, D., Kaufmann, P., \& Calpini, B. (2014). Determination and climatology of the planetary boundary layer height above the Swiss plateau by in situ and remote sensing measurements as well as by the COSMO-2 model. Atmos. Chem. Phys, 14, 13205-13221.

Czepiel, P. ., Shorter, J. ., Mosher, B., Allwine, E., McManus, J. ., Harriss, R. ., ... Lamb, B. . (2003). The influence of atmospheric pressure on landfill methane emissions. Waste Management, 23(7), 593-598.

Czepiel, P. M., Mosher, B., Harriss, R. C., Shorter, J. H., McManus, J. B., Kolb, C. E., ... Lamb, B. K. (1996). Landfill methane emissions measured by enclosure and atmospheric tracer methods. Journal of Geophysical Research, 101(D11), 16711.

Delkash, M., Zhou, B., Han, B., Chow, F. K., Rella, C. W., \& Imhoff, P. T. (2015). Short-term landfill methane emissions dependency on wind. Waste Management, 55, 288-298

EPA (2013) AERSURFACE User's Guide. Report: EPA-454/B-08-001 January 2008 (Revised 01/16/2013)

EPA (2016a) User's Guide for the AMS/EPA Regulatory Model (AERMOD) EPA-454/B-16-011 December, 2016

EPA (2016b) User's Guide for the AERMOD Meteorological Preprocessor (AERMET). EPA-454/B-16-010 December, 2016

Faulkner, W. B., Shaw, B. W., \& Grosch, T. (2008). Sensitivity of Two Dispersion Models (AERMOD and ISCST3) to Input Parameters for a Rural Ground-Level Area Source. Journal of the Air \& Waste Management Association, 58(10), 1288-1296. https://doi.org/10.3155/1047-3289.58.10.1288

Fredenslund, A.M., Mønster, J., Kjeldsen, P., Scheutz, C. Development and implementation of a screening method to categorise greenhouse gas mitigation potential of 91 landfills. Waste Management. In press.

Foster-Wittig, T. A., Thoma, E. D., Green, R. B., Hater, G. R., Swan, N. D., \& Chanton, J. P. (2015).

Development of a mobile tracer correlation method for assessment of air emissions from landfills and other area sources. Atmospheric Environment, 102, 323-330.

Garratt, J. (1994). Review: the atmospheric boundary layer. Earth-Science Reviews, 37(1-2), 89-134.

GMI (2013) European Commission Global Methane Reduction Actions Global Methane Initiative report https://www.globalmethane.org/documents/EC_GMI_reduction_actions.pdf (accessed $7^{\text {th }}$ July 2017) 
GOOGLE EARTH v7.1.8.3036. 2017. Infoterra Ltd. \& Bluesky 2017. Viewed May 2017 <https://www.google.com/earth/index.html>.

Grosch, T. G., \& Lee, R. F. (1999). Sensitivity of the AERMOD air quality model to the selection of land use parameters. Transactions on Ecology and the Environment Www.witpress.com, 29, 1743-3541. Retrieved from https://www.witpress.com/Secure/elibrary/papers/AIR99/AIR99077FU.pdf

Hutchinson, G. L., \& Mosier, A. R. (1981). Improved Soil Cover Method for Field Measurement of Nitrous Oxide Fluxes. Soil Science Society of America Journal, 45(2), 311-316.

Karvounis, G., Deligiorgi, D., \& Philippopoulos, K. (2007). On the sensitivity of AERMOD to surface parameters under various anemological conditions. In 11th International Conference on Harmonisation within Atmospheric Dispersion Modelling for Regulatory Purposes (pp. 43-47).

Long, G. E., Cordova, J. F., \& Tanrikulu, S. (2003). An analysis of AERMOD sensitivity to input parameters in the San Francisco Bay Area. In 13th Conference on the Applications of Air Pollution Meteorology with the Air and Waste Management Assoc. American Meteorological Society, Vancouver, BC, August, 23-25. (pp. 1-4).

Michálek, P., \& Zacho, D. (2012). Effect of surface roughness on neutral and dense gas dispersion in the BLWT. WIT Transactions on Ecology and the Environment, 1, 111-121.

Mønster, J. G., Samuelsson, J., Kjeldsen, P., Rella, C. W., \& Scheutz, C. (2014). Quantifying methane emission from fugitive sources by combining tracer release and downwind measurements - A sensitivity analysis based on multiple field surveys. Waste Management, 34(8), 1416-1428.

Mønster, J.G., Samuelsson, J., Kjeldsen, P., Scheutz, C., (2015). Quantification of methane emission from 15 Danish landfills using the mobile tracer dispersion method. Waste Management, 35, 177-186.

Pachauri, R. K., Meyer, L., Van Ypersele, J.-P., Brinkman, S., Van Kesteren, L., Leprince-Ringuet, N., \& Van Boxmeer, F. (2014). Climate Change 2014 Synthesis Report The Core Writing Team Core Writing Team Technical Support Unit for the Synthesis Report. Intergovernmental Panel on Climate Change. IPCC.

Rees-White T.C., Mønster, J., Beaven R. P., Scheutz, C. 2018. Measuring methane emissions from a UK landfill using the tracer dispersion method and the influence of operational and environmental factors. Waste Management, In press.

Rella, C. W., Crosson, E. R., Dayton, D., Green, R., Hater, G., Lafleur, R., \& Merrill, R. (2009). An Acetylene Tracer-Based Approach to Quantifying Methane Emissions from Distributed Sources Using Cavity Ring-Down Spectroscopy. American Geophysical Union, Fall Meeting 2009, Abstract \#A53C0273,94085 .

Robinson, R., Gardiner, T., Innocenti, F., Woods, P., \& Coleman, M. (2011). Infrared differential absorption Lidar (DIAL) measurements of hydrocarbon emissions. Journal of Environmental Monitoring : JEM, 13(8), 2213-20.

Scheutz, C., Samuelsson, J., Fredenslund, A. M., \& Kjeldsen, P. (2011). Quantification of multiple methane 
emission sources at landfills using a double tracer technique. Waste Management, 31(5), 1009-1017. Shrivastava, A., Gupta, V., \& Article, R. (2011). Methods for the determination of limit of detection and limit of quantitation of the analytical methods. Chronicles of Young Scientists, 2(1), 21-25. https://doi.org/10.4103/2229-5186.79345

Taylor, D. M., Chow, F. K., Delkash, M., \& Imhoff, P. T. (2016). Numerical simulations to assess the tracer dilution method for measurement of landfill methane emissions. Waste Management, 56, 298-309.

The European Pollutant Release and Transfer Register (E-PRTR). (n.d.). Retrieved March 4, 2017, from http://www.eea.europa.eu/data-and-maps/data/member-states-reporting-art-7-under-the-europeanpollutant-release-and-transfer-register-e-prtr-regulation-5 